Portland State University

PDXScholar

10-13-1977

\title{
A Comparison of the Clinician-Client Interactions in Urban Language and Stuttering Clinics
}

Teresa M. Carnese

Portland State University

Follow this and additional works at: https://pdxscholar.library.pdx.edu/open_access_etds

Part of the Speech Pathology and Audiology Commons

Let us know how access to this document benefits you.

\section{Recommended Citation}

Carnese, Teresa M., "A Comparison of the Clinician-Client Interactions in Urban Language and Stuttering Clinics" (1977). Dissertations and Theses. Paper 1158.

https://doi.org/10.15760/etd.1157

This Thesis is brought to you for free and open access. It has been accepted for inclusion in Dissertations and Theses by an authorized administrator of PDXScholar. Please contact us if we can make this document more accessible: pdxscholar@pdx.edu. 
A COMPARISON OF THE CLINICIAN-CLIENT INTERACTIONS

IN URBAN LANGUAGE AND STUTTERING CLINICS

by

TERESA M. CARNESE

A clinical research and demonstration project submitted in partial fulfillment of the requirements for the degree of

\author{
MASTER OF SCIENCE \\ in \\ SPEECH COMMUNICATION:
}

EMPHASIS SPEECH PATHOLOGY AND AUDIOLOGY

Portland State University

1977 
TO THE OFFICE OF GRADUATE STUDIES AND RESEARCH:

The members of the Committee approve the clinical research and demonstration project of Teresa M. Carnese presented October 13, 1977.
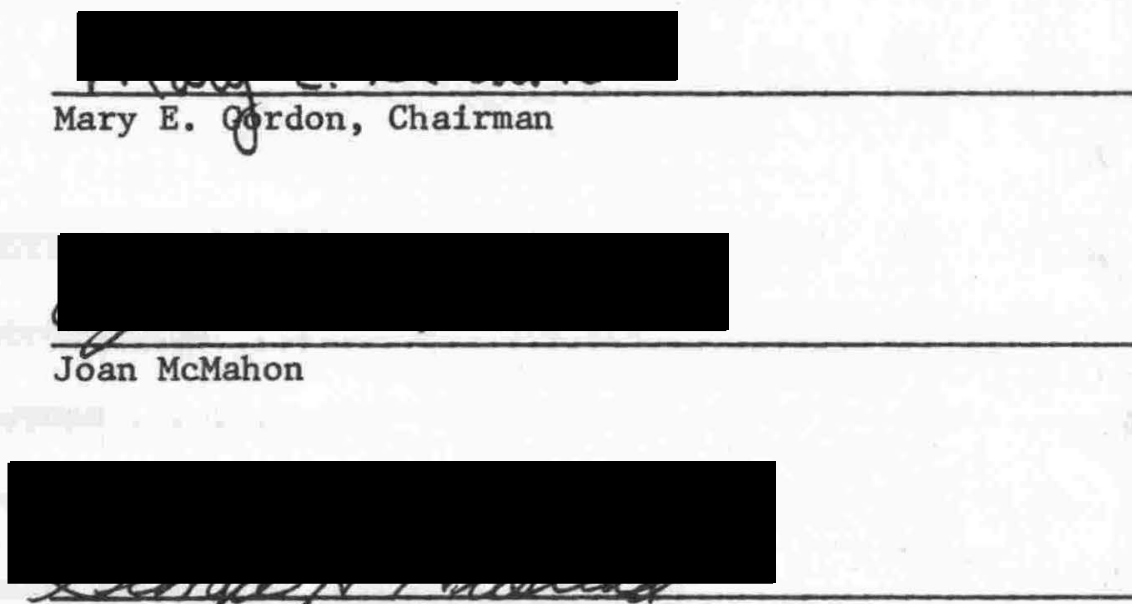

Georgiaf H. Hustead

Mary E. York, Ph.D. 
TABLE OF CONTENTS

PAGE

LIST OF TABLES ................... . . . v

LIST OF FIGURES ................. . . vi vi

CHAPTER

I INTRODUCTION AND PURPOSE .......... 1

Introduction ........... 1

Purpose............. 2

II REVIEW OF THE LITERATURE . . . . . . . 4

Functions of the Clinical Supervisor . . 4

Methods Utilized in Evaluation and

Supervision of Clinicians ...... 5

Interaction Analysis Systems ..... . 9

Communication Disorders and Interaction

Analysis Systems . . . . . . . . 17

Summary ........... . . 21

III PROJECT DESIGN . . . . . . . . . . 22

Subjects . . . . . . . . 22

Instrumentation . . . . . . . 23

Training Procedures...... . . 23

Data Collection Procedures . . . . 25

Data Management and Analysis .... . 27 
IV RESULTS AND DISCUSSION . . . . . . . . . . 29

Comparison of the Total Profiles for Urban

Language Clinic and Stuttering Clinic..... 29

Individual Category Comparison Between

Stuttering and Urban Language C1inicians . . . 33

Individual Category Comparisons Between

Stuttering Clients and Urban Language

Clients............... 41

Difference Analysis by Interaction Ratios . . . 43

The Effectiveness of the Conover Analysis

System ............. . 4 47

Modifications of the Conover Analysis System * 49

Additional Information ......... 50

V SUMMARY AND IMPLICATIONS ............ 52

Summary .................. 52

Implications .............. 53

SELECTED BIBLIOGRAPHY . . . . . . . . . . . . . . . . 54

APPENDICES ....................... . . . 57 


\section{LIST OF TABLES}

TABLE

PAGE

I Spearman RHO Rankings for Urban Language and

Stuttering Clinics ........... . . 30

II Interaction Summary -- Stuttering Clinicians VS. Urban Language Clinicians .......... 32

III Mann-Whitney A Test of Individual Categories . . . 34

IV Sequence Summary -- Stuttering Clinicians vs. Urban Language Clinicians ........... 44 


\section{LIST OF FIGURES}

FIGURE

PAGE

I Graph of Category Percentages for Stuttering

Clinic and Urban Language Clinic . . . . . . . . .

II Adaptation of Gordon's (1975) Conover Analysis System Data Sheet by Teresa Carnese (1977) . . . . . . 


\section{CHAPTER I}

\section{INTRODUCTION AND PURPOSE}

\section{Introduction}

Professionals in the field of speech pathology have been concerned with the lack of emphasis placed on the role of the clinical supervisor. Van Riper (1965) so aptly stated this concern, "We fear we discern a general tendency in our field to view supervision of clinical practice as being of much less importance than teaching or research." Often the clinical supervisor is the least educated and has the most limited amount of clinical experiences in relation to the rest of the training institution staff (Schubert, 1974). Also, clinical supervisors seldom have coursework in supervision (Stace and Drexler, 1969). Currently, the profession is placing more emphasis on the role of the clinical supervisor as evidenced by the increased number of supervisory sessions held at the 1976 American Speech and Hearing Association in Houston, Texas.

The role and function of clinical supervisors have been rather nebulous. Providing students with some kind of feedback, concerning their skills and interaction with their clients, appears to be one of the main functions of the clinical supervisor (Haller, 1967; Geoffrey, 1973; Payne and Koller, 1974; and Culatta et a1., 1975). C1inica1 supervisors have expressed a desire to have more objective methods for providing their students with feedback, rather than the more traditional 
subjective methods of evaluation (Klevans and Volz, 1974).

In recent years interaction analysis systems, which originated as

techniques for teachers to quantify classroom behavior, have been adapted for assessing clinician and client interactions in the clinical sessions (Boone and Prescott, 1972; Schubert et al., 1973; and Conover, 1974). If such clinical sessions are viewed as an interaction between the clinician and client, observers are looking at the influence of one behavior upon another behavior. By recording and analyzing this interaction, the clinical supervisor and/or student clinician can better determine the efficacy of any given management technique and/or session (Conover, 1974).

Research has indicated that interaction analysis systems are useful methods for analyzing clinician-client interaction by individuals in numerous settings and with varying levels of expertise (Prescott, 1970; Boone and Prescott, 1972; Butler, 1974; and Golper, 1976). Also, clinical supervisors or clinicians may analyze three minutes of any given management session with confidence that it is a representative segment of the entire interaction (Schubert and Laird, 1974). Published research comparing the effectiveness of using interaction analysis systems with clients of various disorders, however, has been minimal.

\section{$\underline{\text { Purpose }}$}

The purpose of this clinical research project was to use an interaction analysis system to compare the behaviors of clinicians and their clients with two types of communicative disorders and to determine how the clinicians utilized their clinical time. More specifically, this study employed the Conover Analysis System (Conover, 1974) and compared the client-clinician behaviors in the Portland State University Urban 
Language Clinic and Stuttering Clinic. The data which were gathered provided a baseline of the client-clinician behaviors in the two clinical settings. No effort was made to assess the value of the various categories of behavior.

The primary question examined was:

1) How do the clinicians use their clinical time in Stuttering Clinic and in Urban Language Clinic?

The following secondary questions were posed:

2) Is the Conover Analysis System effective as an objective method of observing the interaction of clinicians and their clients in each of the two different clinical settings?

3) Are there modifications of the Conover Analysis System that would facilitate the recording of clinician-client interaction in either of the clinical settings? 
CHAPTER II

REVIEW OF THE LITERATURE

\section{Functions of The Clinical Supervisor}

The American Speech and Hearing Association (ASHA) presently stipulates that student clinicians must have a specified number of hours of supervised clinical practicum (ASHA, 1976). It also specifies that at least one-fourth of the practicum must be directly supervised, i.e., observed by the clinical supervisor who must have the Certificate of Clinical Competency in the area being supervised. Beyond this, the nature, quality, and degree of supervision are not stipulated.

Generally speaking the clinical supervisor interacts with the student clinician to discover the most productive methods of affecting the diagnostic or therapeutic relationship (Ward and Webster, 1965a and 1965b). In addition to aiding the student in developing skills, according to Halfond (1964), the supervisor should recognize areas and methods in which the student's character problems enter in the therapeutic relationship and assist the student in overcoming resistances to learning. Miner (1967) and Schubert (1974) agree the supervisor should know and utilize a variety of materials, methods and techniques in his/her role of training students to be speech clinicians. Miner further adds that clinical supervision entails:

1) Understanding and utilizing the dynamics of human relationships which promote the growth of the student clinician. 
2) Appreciating the individual differences among student clinicians to such an extent that supervisory programs and practices may be radically altered to suit his needs.

3) Establishing realistic goals with the student clinician which are clearly understood by both student and supervisor.

4) Observing and analyzing the teaching-learning act involved in the therapy procedures.

5) Providing the student with the necessary 'feedback' which will enable him to become increasingly self-analytical.

6) Recognizing and setting aside the supervisor's personal prejudices and biases which influence perception and develop rigidity in order that the subjective task of evaluation may become as objective as possible.

In summary the function of the clinical supervisor is to evaluate, encourage, reinforce, coordinate, facilitate and moderate the clinical process (Anderson, 1974).

\section{Methods Utilized In Evaluation And Supervision of Clinicians}

Review of the literature in speech pathology reveals little research has been conducted relative to supervisory techniques and methods for evaluating students' progress (Halfond, 1964 and Boone and Prescott, 1972). Perhaps Van Riper (1965) offered an explanation for the lack of information when he stated, "We do not feel that it is either possible or wise to spell out specific procedures for supervision of casework." Students vary in their needs for counsel. Likewise, supervisors differ among themselves in their manner of supervision.

A major function of the clinical supervisor is to provide feedback to the clinician concerning his/her capabilities in a variety of parameters relating to the effectiveness and success of clinical interaction. A number of researchers (Brooks and Hannah, 1966 and Payne and Koller, 1974) have found that immediate feedback, via the use of an induction loop and hearing aid or wireless microphone and receivers, provides a means of not only reinforcing a clinician's behavior but a method for 
suggesting alternative procedures throughout the clinical session. Brooks and Hannah (1966) Indicated that a possible pitfall of the induction loop and hearing ald is the clinical supervisor's tendency to provide too much input or feedback, thereby dominating the clinical session. Geoffrey (1973) stated that verbal feedback or critique, although not necessarily immediate, is used extensively in all observational settings including direct in-the-room observation, behind a two-way mirror, and audio and videotape recordings. Written feedback is also utilized in many observational settings, but to a lesser degree than verbal. According to Geoffrey, the "behind the two-way" mirror observational setting is the only one in which written feedback was provided by more supervisors than verbal feedback.

A supervisor-student conference is another situation during which feedback is imparted to the student clinician. Culatta et al. (1975) revealed that supervisors believe the more time reserved for each student clinician for conferences, the more pleased the student would be; however, students in the same study, expressed need for supervisory conferences only at "critical points" in intervention. The majority of supervisors who engage in student conferences provide students with verbal feedback while a lesser number utilize written feedback (Geoffrey, 1973).

Varied techniques and criteria are utilized in evaluating student clinician interactions with their clients. Subjective methods of evaluation have been the most common technique for determining clinical effectiveness with a growing trend toward developing objective systems of analysis (Klevans and Volz, 1974). Typical subjective evaluation procedures have ranged from rating students on a list of attributes, including dependability and clinical rapport, to writing lengthy comments 
about their clinical interaction (Klevans and Volz, 1974). To make an objective clinical evaluation, various forms and scales for evaluating clinicians have evolved.

Haller (1967) devised such an evaluation form. He requested eighteen field supervisors holding the Certificate of Clinical Competence to rank eighteen criteria regarding clinical performance on a one to eight point continuum from "greatest importance" to "of no importance." Fourteen of the efghteen criteria were retained for the Clinician's Rating Scale. Broad categories for evaluation included: clinical rapport, relates well, time management, knowledge of clinical procedures, and personality factors demonstrated. The four criteria which were dropped from the scale were: relates with parents, relates with other clinicians, personal appearance, and stays within time limits.

In a somewhat similar format, Brown (1967) formulated an evaluation form which includes personal characteristics, diagnosis, therapy, and progress. It is interesting to note that progress referred to the clinician's growth throughout the term and his/her ability to seek and utilize advice. These evaluation forms are discussed in seminar so the students understand what is expected of them.

The Practicum Evaluation Form developed by Klevans and Volz (1974) lists twenty-five competencies for student clinicians. The general categories are similar to the two scales already discussed: diagnosis and reporting, developing and planning management, interacting with clients, and personal and professional qualities. The authors took their form one step further and evaluated each of the twenty-five competencies on a scale from 1-7 with 1-3 representing minimal levels, 4-5 indicating 
intermediate levels, and 6-7 representing superior levels of competencies. For each of the twenty-five categories, descriptions of expected behavIors at each level are provided.

Three possible subjective evaluation forms have been described above as tools utilized in determining student clinician competencies. Although there has been an effort to objectify these forms (Klevans and Volz, 1974), some elements of both supervision and evaluation of clinical processes are undeniably subjective; the authors suggest perhaps this is Inevitable and probably desirable.

In recent years clinical supervisors have expressed a need for more objective techniques for evaluating the clinician-client dyad. Observing and evaluating behavior using audiovisual films, closed-circuit television, kinescope film, and videotapes have provided obvious advantages over personal or direct observation (Boone and Stech, 1970; Irwin and Nickles, 1970; and Schultz, 1972). One advantage is that clinical supervisors may comment at the time behavior is observed rather than interrupting those involved in management (Irwin and Nickles, 1970). Boone and Stech (1970) noted the following advantages: 1) immediate and continuing re-usable playback; 2) clear pictures with natural lighting; 3) instant correction by retaping; 4) mobility of equipment; 5) stop framing capability; and 6) preservation of the intervention sessions as long as needed.

Audiotape is also an effective means of monitoring verbal behavior. Although it is readily avallable to most clinicians, it is seldom used in training programs for instructing and evaluation of the clinical process (Diedrich, 1966). Although videotaping and audlotaping allow the clinical supervisor to discuss specific aspects of the clinician and client 
interaction as they are occurring, the behavior is not quantified.

Interaction analysis is a system for the supervisor and/or the clinician to objectively record the observed clinical behavior for immediate analysis or analysis at a later time (Schubert and Laird, 1974). Recording of behavioral events may be made during direct observations, audio tape, or videotape recordings.

According to Kunze (1967), there are distinct advantages for recording behavioral events rather than impressions: 1) listing behavioral events preserves data which are lost when only impressions are noted; 2) recording of behavioral events preserves data which may have no importance when considered in isolation, but which assume importance in relation to other behaviors emitted at other times; 3) when impressions are recorded, a conclusion is made on the basis of the one behavioral event just observed or on a sequence of events, vaguely remembered; and 4) behavior events are objective records, and therefore cannot be distorted by observer bias. In contrast, impressions, being of a subjective nature, may be affected by the observer's personal bias.

\section{Interaction Analysis Systems}

Interaction analysis originated as a method for recording quantitative and qualitative dimensions of verbal interaction in the classroom setting (Amidon and Hough, 1967). One of the earliest techniques for analyzing teaching behavior was developed by Anderson (1967). His study sought to develop methods for recording and assessing dominative and integrative behavior of teachers in contact with kindergarten children. Withall (1967), in a later study, was one of the initial researchers who categorized teacher statements to determine the social-emotional climate 
of the classroom. His work indicated that classroom climate could be assessed and described by a category system. Amidon and Hough (1967) reported on Interaction Process Analysis, a technique developed by Bales for assessing the interaction of members in small group settings.

Another system of interaction analysis for the classroom setting was developed by Amidon and Flanders (1967). This system was an outgrowth of research by Flanders on teacher statements. The three major classifications in this system are teacher talk, student talk, and silence or confusion. Teacher verbal behavior is subdivided into indirect and direct teacher talk. Indirect influence consists of four categories: 1) accepting feelings, 2) praising or encouraging, 3) accepting ideas, and 4) asking questions. The validity of using the four indirect influence categories as an objective method for determining classroom interaction is questioned. These categories lend themselves to subjective, rather than objective, evaluations. Research to confirm high interjudge reliability between observers, and high intrajudge reliability, over time by one observer, is needed to determine the efficacy of these categories. Direct influence yields three categories: 5) lecturing, 6) giving direction, and 7) criticizing or justifying authority. Student talk has two subdivisions: 8) responding to teacher, and 9) infitiating talk. The last major section, silence or confusion, was not subdivided further, but was designated to represent anything that is not teacher or student verbal interaction. A definition of each category including its corresponding behavior was provided. Individuals utilizing this system record numbers corresponding with each category, every three seconds, in the sequence of the verbal behavior observed. 
In the field of speech pathology a number of interaction analysis systems, which appear to be designed upon the Amidon and Flanders (1967) model, have been developed to describe clinician-client behavior in the clinical setting. A Multidimensional Scoring System was developed by Johnson (1969) who sought to account for both verbal and nonverbal forms of communication. This system was based on five general areas: cognitive, responsiveness, tactual, visual and auditory. From these five general areas, Johnson developed a forty-category system with a description and corresponding numerical number for each category. He stated intra-judge reliability was high indicating consistent use of this instrument from one time to another in identifying behavioral events, modality events, and scoring items. He also reported that inter-judge reliability was low, as he had anticipated, because the observers used the scoring systems differently as a result of their own philosophies and clinical biases. Apparently the categories allowed for subjective value judgement. It would seem, however, a more desirable category system would be one that permits high inter-judge reliability, but would be sensitive to differences in the clinical process (Prescott, 1970).

A ten-category system was used by Boone and Goldberg (1969) to study the clinical acquisition of behavioral principles by videotape self-confrontation. This system, developed by Stech (1969), included five clinician categories and five client categories (See Appendix A). The sequence of behavioral events is graphically preserved by first placing a horizontal line in the appropriate column designated for a particular event which is indicated by another horizontal one in the corresponding column. Refer to Appendix B. High inter-judge reliabiltiy was 
found between judges utilizing this system to score videotaped recordings of clinical interaction (Boone and Goldberg, 1969).

Prescott (1970) indicated only a limited amount of information could be obtained from the broad categories of the Boone and Goldberg (1969) system of analysis. He developed a nineteen-category matrix, upon a general operant frame of reference, that would quantify behaviors within the clinical speech setting. The Prescott system included twelve clinician categories and seven client behaviors (see Appendix C) recorded in a continuous line method as described by Boone and Goldberg. Both high intra-judge and inter-judge reliability indicated this system has considerable value as a method for evaluating clinical effectiveness. They concluded this system appeared to have considerable merit for describing the clinical process in speech intervention and training of clinicians in speech therapy.

Boone and Prescott (1972) developed the Content and Sequence Analysis System as a modification of the Boone and Goldberg (1969) system. It was utilized to train student clinicians to score their own clinical sessions. This ten category system (refer to Appendix D), comprised of five clinician and five client categories, was used by clinicians to analyze audiotaped and videotaped segments of management. At the same time, Boone and Prescott (1972) developed a Speech and Hearing Therapy Session Scoring Form (Appendix E), which not only summarized the total number of events for each category, but also listed the number of certain behavioral sequences. Once the individual categories have been calculated a number of ratios can be computed to determine the percentage of correct responses, incorrect responses, good evaluatives, bad evaluatives, inappropriate responses, direct control (by the clinician), and 
socialization (by both the clinician and client) throughout the session. The Content and Sequence Analysis System thus is a measurement tool to make cliniclans aware of what they and their cllents are doing during a clinical session. This scale and those similar to it do not describe the "why" of the behavioral events. A system describing the "why" of behavioral events, most likely, would not be a simple numerical or alphabetically coded method of looking at clinican/client behaviors. In addition, looking at the "why" of behavioral events would tend to be a subjective evaluation. Interaction analysis systems were designed to eliminate as much as possible subjective evaluations.

The Analysis of Behavior of Clinicians (ABC) is a time-based behavioral recording system developed by Schubert, Miner, and Till (1973). It is a twelve category system. Clinician behaviors are described in the first eight categories and the action of the client is listed in categories nine through eleven. The twelfth category, silence, is utilized when both the clinician and the client display no verbal or relevant nonverbal behavior (Schubert and Laird, 1974). Appendix F 1ists the categories and their descriptions. Recording of events occurs every three seconds rather than continuously recording clinician-client events so that the behaviors may be quantified, analyzed and, when appropriate, modified (Schubert and Laird, 1974).

Conover (1974) subsequently designed the Conover Analysis System. This system evolved because of the limitations she found in both the Content and Sequence Analysis system and the ABC system. Conover stated that the continuous line charting of the Boone-Prescott Content and Sequence Analysis (1972) system is difficult to manage in a darkened observation room. Also, the three-second time delay and the number of 
categories in the $A B C$ (1973) system yield distracting elements to a charting observer. As a result of these limitations, a recording system utilizing fewer categorles and employing alphabetical symbols, as opposed to numbers and graphs, was developed. Appendix G is a description of the eleven categories and a listing of their respective alphabetical symbols, for the Conover Analysis System (Conover, 1974).

According to Conover, clinical research and experience have demonstrated the fewer categories involved, the easier the recording process is to learn and utilize. The eleven categories thus were chosen by Conover (1974) as the smallest number necessary to provide the most information about the kinds of relevant verbal, clinician and client interaction within the clinical setting.

In the Conover system, an alphabetical symbol is charted for every verbal response observed by the recorder. There is no time lag, as in the ABC system (Schubert et al., 1973), because of the possibility of missing what stimulus preceded what response and vice versa. Charting should occur during the mid-point of management rather than the beginning or end where there may be a high degree of socializing, which is not representative of the session (Conover, 1974). Charting may be in either a linear or horizontal manner (see Appendix H). The recorder must chart the clinician-client verbal behavior in the sequence in which it occurs, rather than separately recording clinician or client behavior, i.e., two individual colums. Recording in a single continuous line allows one to see not only who was talking but what response followed what stimulus (Conover, 1974). 
Analysis of the recorded data includes counting the total number of responses made by both the clinician and client, what percentage of these were made by the cliniclan and what percentage by the client, what percentage each client category is of the total client responses. This is similar to the format used by Boone and Prescott (1972), excluding the sequence of behaviors and ratios. When comparing The Conover Analysis System (Conover, 1974) to others, 1t appears to have some advantage in else of charting clinician and client verbal behaviors. However, according to McMahon (1977), although the Conover Analysis System seems to be easier to learn than the Boone-Prescott Content and Sequence Analysis System, the latter is faster when charting in horizontal colums. The Conover system appears to be easier to learn because it is an alphabetically coded system rather than numerically coded. On the other hand, the Boone-Prescott system seems quicker to chart because it involves recording a one-digit number for ten of the eleven possible categories; whereas the Conover system requires recording one alphabetically coded symbol for seven categories, and recording two alphabetically coded symbols for the remaining four categories.

Experimenters, clinical supervisors, and clinicians have been interested in various aspects of the behavior interaction of a management session. Schubert and Laird (1974) conducted a study to determine the minimum length of time necessary to obtain a representative sample of clinician-client interaction in the clinical setting. Graduate students conducting articulation and/or language intervention were observed utilizing the Analysis of Behavior of Clinicians (ABC) System (Schubert et a1., 1973). Behavior was recorded every three seconds for the middle fifteen minutes of thirty-five minute management sessions. The results 
indicated that a three-minute period was an adequate length of time to obtain an accurate sample of a clinical session. This means that clinical supervisors or clinicians could analyze data from three minutes of intervention and be confident that it is a representative sample of the clinician-client interaction throughout that management session (Schubert and Laird, 1974).

Interaction analysis systems have been found to be objective methods of analyzing clinician-client interaction by individuals in a variety of settings and at different levels of expertise. In a study by Golper (1976), speech pathology students who had no clinical practicum were trained to observe clinician-client behaviors utilizing the BoonePrescott Content and Sequence Analysis System. The Investigator concluded that students without prior knowledge of what to look for when observing the management process, could be trained to focus on and objectively analyze certain behaviors in the clinical interaction.

Clinical supervisors may have benefited most from using interaction analysis systems. Analysis systems have provided them with a tool to provide feedback to their clinicians in regard to areas of behaviors that may need to be altered to produce more effective clinician-client interaction (Prescott, 1970).

Boone and Prescott (1972) also reported their Content and Sequence Analysis System is a method for student clinicians to monitor their own interaction with their clients. Thus, student clinicians using audiotape or videotape self-confrontation may analyze their own management processes without the aid of a clinical supervisor.

Interaction analysis systems may be of particular use to the practicing clinician in the public schools, clinics, and hospital settings 
where interaction with another speech clinician is not possible; therefore, self-analysis is a necessity. Butler (1974) found that utilizing the Boone-Prescott Content and Sequence Analysis System during his Clinical Fellowship Year was a reinforcing experience. Using audiovisual self-confrontation, he confirmed his own positive feelings about his interaction with his clients and was able to provide the administration with a documented form of his performance. The use of interaction analysis systems, therefore, is not relegated only to clinical supervisors, but may be used by students and speech clinicians practicing in the field.

\section{Communication Disorders And Interaction Analysis Systems}

There has been a limited amount of research utilizing interaction analysis systems to detect the existence of differences and similarities in category usage, within clinician-client dyads, based on the nature of the communicative disorder. Prescott (1970) reported on the interactions of cliniclans and their clients comparing the following disorders: voice-language, voice-prosody, voice-articulation, languageprosody, language-articulation, and prosody-articulation. He used a nineteen-category system, which was an outgrowth of a system used by Boone and Goldberg (1969) to analyze the clinician-client interaction. According to Prescott the language clinicians' interactions differed significantly from the prosody clinicians in the following categories: POSITIVE REINFORCEMENT (Social-Verba1), CORRECT RESPONSE, INCORRECT RESPONSE, and INAPPROPRIATE RESPONSE. These data suggest there may be differences in regard to the clinical interaction of clinicians with clients of varied communicative disorders. These results further 
indicate a need to determine the differences in behavioral interaction for clinicians working with clients demonstrating different types of communication disorders and the nature of any similarities and differences that may be identified (Prescott, 1970).

In a later study, 01sen (1972) pursued the Implications of Prescott's study using the Prescott nineteen category scoring system to study four parameters of speech remediation: children with articulation disorders, children with delayed language disorders, adults with prosody (stuttering) disorders, and adults with voice disorders. He determined, for each disorder, category totals and percentages, interaction ratios, and sequential patterns of interaction for both the inexperienced and the experienced clinicians comprising his study. Olsen compared clinicians and their respective clients demonstrating one type of communicative disorder with clinicians interacting with clients of a different disorder. Those data most pertinent to the present clinical research project were the results obtained from the comparison of clinicians remediating prosody (stuttering) disorders with clinicians managing delayed language. The results indicated language clinicians utilized a greater percentage of the total interaction time when compared with prosody clinicians. In addition, there were a greater number of both clinician and client interactions during language remediation when compared with clinician-client interactions during prosody management. Clinical experience did not appear to be a factor; both experienced and inexperienced language clinicians interacted more frequently than prosody clinicians with similar clinical expertise (01sen, 1972). 
01sen's study discussed difference analysis by categories between experienced prosody clinicians and language clinicians. 0lsen stated the categories of AUDITORY MODELS, VISUAL MODELS, AUDITORY-VISUAL MODELS, GOOD EVLAUATIVE (Tangible), BAD EVALUATIVES (Socia1-Verba1), and INCORRECT RESPONSE were utilized more in language management than prosody remediation. In contrast, the categories of GOOD EVALUATIVES (SocialVerba1), GOOD EVALUATIVES (Social-Nonverba1), CORRECT RESPONSE, GOOD SELF EVALUATIVES and BAD SELF EVALUATIVES were used more in prosody remediation than language management. Comparisons of the remaining categories indicated 1ittle difference between the experienced language and prosody clinicians.

It appears, clinical experience was not a determining factor in how the clinicians in language and prosody remediation utilized their time. A comparison of inexperienced language clinicians yielded similar information when compared with experienced clinicians interacting with the same disorder. Inexperienced language clinicians, like experienced prosody clinicians utilized the following categories of AUDITORY-VISUAL MODELS, GOOD EVALUATIVES (Tangible), BAD EVALUATIVE (Social-Verbal), and INCORREDT RESPONSES more frequently than inexperienced prosody clini- cians. In addition, inexperienced language clinicians used NO EVALUATIVE and NEUTRAL/SOCIALS categories more often than inexperienced prosody clinicians. Inexperienced prosody clinicians used the same categories as experienced prosody clinicians, with no exception.

A comparison of clinician-client interaction ratios for inexperienced language and prosody clinicians indicated language clinicians' ratios were higher for all interaction ratios except Correct Response. The percentage of difference between each interaction ratio varied 
from less than 3 percent to more than 45 percent between clinics with the following ratios being higher for language clinic: Approximation, Incorrect Response, Good Evaluative, Bad Evaluative, Inappropriate, Direct Control and Socialization (01sen, 1972).

A comparison of experienced language clinician ratios with experienced prosody clinicians revealed more divergent findings. Language clintcians had higher percentages for the following ratios of events: Approximation, Incorrect Response, Inappropriate, Direct Control, and Socialization. Prosody clinicians had higher percentages for the ratios of Correct Response, Good Evaluative, and Bad Evaluative.

It appears the age of the client may be an important factor indicated by the higher percentages in the categories of Inappropriate, Direct Control and Socialization for both inexperienced and experienced language clinicians. It would seem, the children in language remediation would demonstrate more inappropriate behavior, socialization, therefore require more direct control of the management session, by their clinicians, when compared with clinicians interacting with adults.

It may be conjectured clinical experience is an important factor influencing the prosody clinicians in their ability to determine the correctness or incorrectness of their clients responses. A higher percentage of both Good and Bad Evaluatives were noted with experienced prosody clinicians than experienced language clinicians. Conversely, inexperienced language clinicians rated higher ratio percentages than inexperienced prosody clinicians on the same categories. 
Summary

The research on clinical supervision suggests a continuing need for methods to supervise and evaluate the speech management process (Boone and Prescott, 1972; Schubert et a1., 1973; and Conover, 1974). For years subjective methods of evaluation were the only tools clinical supervisors utilized in providing clinicinas with feedback and in assessing the clinician-client interaction (Brown, 1967; Haller, 1967; and Klevans and Volz, 1974).

In more recent years interaction analysis systems have been developed as techniques for more objectively describing the behavioral interaction between clinicians and their clients. These systems have been useful not only to clinical supervisors, but to student clinicians and speech clinicians practicing in the field, for purposes of selfevaluation.

There has been minimal research comparing clinicians use of their clinical time when dealing with clients demonstrating different communicative disorders. There is a need for this kind of information in order to determine whether interaction analysis systems are effective tools for analyzing clinicians' interactions with clients demonstrating different communicative disorders. Also, this information could provide a baseline of behavioral interactions anticipated when clinicians are working with a particular disorder, when utilizing similar management procedures. 


\section{CHAPTER III}

\section{PROJECT DESIGN}

\section{$\underline{\text { Subjects }}$}

The subjects for this research project consisted of seven experienced student clinicians and their respective clients enrolled for clinical practicum at Portland State University during Winter term, 1977. The term "experienced" indicated the above-mentioned clinicians had prior clinical practicum in at least one other clinic. Although there were seven clinicians involved in this clinical research project, one clinician was enrolled in both Urban Language Clinic and Stuttering Clinic, enabling data to be computed for eight cliniclan/client dyads. The clinicians were divided into two groups. Group I was comprised of four clinicians enrolled in Urban Language Clinic. Their respective clients consisted of four preschool children who attended St. Vincent De Paul Day Care Center. Their management was directed toward school readiness skills, such as concept development of colors, numbers, prepositions, and body parts. Group II was comprised of four clinicians enrolled in Stuttering Clinic. Their respective clients were four adults. The primary management objectives for the clients were to learn relaxation techniques and to obtain fluency. The clinicians utilized Casteel's (1974) four-stage program, "Modification of Stuttering Through a Series of Discrimination Tasks" to obtain fluency. Jacobson's progressive relaxation (1929) techniques were used to enable the clients 
to discriminate degrees of tension.

The clinicians in both Urban Language Clinic and Stuttering Clinic used behavior modification techniques in their management programs.

\section{Instrumentation}

The investigator collected data using the Conover Analysis System (Conover, 1974), a system which uses an alphabetical code to represent specific types of clinician-client behavioral interaction (see Appendix G, p. 65). The factors in the selection of this system rather than other anlaysis systems were: 1) the use of fewer categories enabling easier charting, yet yielding maximum information; 2) the use of alphabetical rather than numerical codes, facilitating easy learning and use of the charting system; and 3) minimal amount of published research utilizing this method. The last factor appeared important because the Conover system is used quite frequently at Portland State University; yet the investigator did not find any research substantiating the efficacy of the Conover Analysis System.

\section{Training Procedures}

Randomly selected, five minute, videotaped and live-site segments of both Urban Language and Stuttering Clinics were used for training purposes. Through the use of videotapes, instruction and practice, the investigator demonstrated competency in the tracking procedures. The investigator calibrated her recording of clinical behaviors using the Conover Analysis System with two clinical supervisors.

Inter-judge reliability of recording was determined for 4 twominute videotaped segments, two for each clinic. The investigator and 
the two judges (clinical supervisors) independently recorded the events for the identical videotaped segments of Urban Language and Stuttering Clinics. Inter-judge reliability was computed by using the Spearman RankOrder Correlation Coefficient (RHO) for each pair of judges across the trial data $($ eleven categories $=N)$. The inter-judge correlation coefficients for the two Urban Language Clinic segments were .94 and .96 between the investigator and judge number one, and .94 and .91 between the investigator and judge number two. The inter-judge correlation coefficients for the two Stuttering Clinic segments were .98 and .92 between the investigator and judge number one and 1.00 and .98 between the investigator and judge number two. The correlation coefficients for the Stuttering Clinic segments, between the two judges, were .99 and .98 , and for the Urban Language Clinic segments, .98 and .93 . These data indicated a high degree of similarity between the independent scoring of the investigator and judges, therefore yielding very high interjudge reliabilities.

After the investigator and the two clinical supervisors reached a high level of agreement in tracking videotaped clinical sessions, the investigator established intra-judge reliability. Proficiency in recording the behaviors observed were determined by four intra-judge reliability checks using videotaped segments, two for each clinic. Each of the four segments were viewed and recorded twice, with a one week time interval between the two viewings of the same segment. Three of the segments were five minutes in length, and one of the Urban Language segments was four minutes long. At that time, two five minute segments of Urban Language Clinic remediation were not avallable to the investigator. The shorter length of the videotaped segment did not 
appear to invalidate the results since there were a higher number of interactions during the one four minute segment than any of the five minute segments. Intra-judge reliability was computed using the Spearman RHO test. The intra-judge correlation coefficients for the Urban Language segments were .98 and .98 and, for the Stuttering segments, were .95 and .85 . This suggests a high level of agreement between observation segments.

\section{Data Collection Procedures}

The behaviors of each clinician-client dyad were recorded using the Conover Analysis System during three separate clinical sessions, with at least one week, but not more than two weeks, between each observation. A randomly selected five-minute segment approximately midway through each session, was tracked. The investigator observed the clinician-client dyads at least five minutes prior to tracking in order to view the management techniques employed, and determine the goals for the session. With the exception of one session, the investigator tracked each clinical session via live, indirect observation behind a two-way mirror. The investigator was in the darkened observation room viewing clinician-cllent interaction in various clinic rooms, through a two-way mirror. Due to unplanned circumstances the investigator obtained one of the Urban Language clinicians five minute segments by direct observation in the clinic setting. In addition, the clinician and client were being videotaped for the entire session. The validity of this session's results is questioned by the investigator because of the investigator's presence during the session. 
Behaviors were recorded using a vertical alphabetical coding system. In other words, as each interaction was observed it was recorded on the recording sheet, beneath the preceding behavior in columnar style.

Verbal responses were recorded in "sentencing units" indicating that each statement by the clinician or client was denoted by one alphabetical code (Golper, 1976). For example, if the clinician were to exclaim, "Super! You did a nice job! Let me shake your hand!" in response to a correct utterance by the client, these were rated as three spearate POSITIVE REINFORCEMENTS, 1.e., three "PR's" were recorded. Verbal responses for stuttering clients reading a paragraph were likewise recorded in sentence units. Although a stuttering client may not pause at the end of a sentence, but continue to speak running the last word of one sentence into the initial word of the next sentence, the investigator made a judgement and recorded each individual sentence as one response. Therefore, each sentence read by the client was recorded as either a CORRECT RESPONSE or INCORRECT RESPONSE.

During the process of recording behavioral events the investigator noted the stuttering clients not only asked questions (Category Q), but also made self-evaluations regarding the correctness or the incorrectness of their responses. Since these self-evaluations often did not follow a specific stimulus (Category ST) from the clinician, the investigator did not consider them to be correct or incorrect responses. The Conover Analysis System (1974) does not specify a category for client self-evaluation; therefore, this investigator recorded all selfevaluations under the QUESTION category. 
The investigator recorded all clinician "verbal junk", e.g., "um, alright, and 0.K." under the SOCIAL (So) category because those responses were not considered either reinforcing or necessary to the remediational process.

\section{Data Management And Analysis}

For each five-minute segment, the investigator tallied the total number of events for each category of clinician and client behavior, and the percentage of each category of clinician and client behavior, and the percentage of each category of the total number of events. In addition, three sequence counts and the number of responses per minute were calculated. The investigator also computed seven behavioral ratios to determine the percentage of occurrence of a particular behavior in comparison to other specific behaviors (see Appendix I). Appendix J is the form that was used to record category counts, percentages, sequence counts and ratio scoring computed for each session. This form, the Conover Analysis System Session Scoring Form, was developed for Gordon (1975); it is an adaptation of the Boone-Prescott (1972) Speech and Hearing Therapy Session Scoring Form.

The means of the total number and percentages of each behavioral category, behavioral ratio and number of responses per minute were computed. These data were illustrated in a graph for visual comparison. A correlation of the entire profiles for each of the two clinics using the category frequancy data was computed using the Spearman Rank-Order Correlation Coefficient (RHO) (Williams, 1968 and Mendenhall, 1971). This statistic was used to determine if there was a significant difference, overall, in how the clinicinas in each clinic utilized their 
remediation time. The Spearman RHO also was used to determine if the one subject, who was a clinician in both clinics, utilized her clinical time for both clinics in a significantly different manner.

The Mann-Whitney U statistic (Downie and Heath, 1959) was used to determine if there were significant differences between individual categories in how the clinicians in each clinic used their clinical management time (Grove, 1976). 
CHAPTER IV

RESULTS AND DISCUSSION

\section{Comparison of The Total Profiles For Urban Language Clinic And Stuttering Clinic}

The primary question investigated in this clinical research project was: How do the clinicians use their clinical time in Stuttering Clinic and Urban Lauguage Clinic? The Conover Analysis System (Conover, 1974) was used to record the interactions of clinicians and their respective clients in both Stuttering Clinic and Urban Language Clinic at Portland State University. The resultant data were the basis for the statistical analysis and the following results.

The Spearman Rank-Order Correlation Coefficient (RHO) was utilized to determine the correlation between the two settings relative to the usage of clinical management time. The eleven category counts recorded in Urban Language Clinic and Stuttering Clinic were ranked and compared (Refer to Table I). The resultant Spearman RHO was .81, a high positive correlation which is significant at the .02 level of confidence. This suggests the clinicians in both clinics used their clinical remediation time in a similar manner. See Figure I for a graphic display of the total percentages.

Table II compares total events and percentages for the category counts for the Urban Language clinicians with those of the Stuttering clinicians. Although there were a larger number of interactions noted in Urban Language Clinic, approximately 400 more, the percentages of the 
TABLE I

SPEARMAN RHO RANKINGS FOR URBAN

LANGUAGE AND STUTTERING

CLINICS

\begin{tabular}{lcccc} 
Categories & $\overline{\mathrm{X}}$ & $\begin{array}{c}\text { Urban Language } \\
\text { Ranking }\end{array}$ & $\overline{\mathrm{x}}$ & $\begin{array}{c}\text { Stuttering } \\
\text { Ranking }\end{array}$ \\
\hline Q & .33 & 1 & 2.25 & 3 \\
P & 2.00 & 2 & 2.23 & 2 \\
M & 3.00 & 3 & 4.50 & 6 \\
A & 4.16 & 4 & .75 & 1 \\
IR & 5.91 & 5 & 3.33 & 5 \\
S & -6.33 & 6 & 2.66 & 4 \\
I & 7.08 & 7 & 14.25 & 10 \\
SO & 7.75 & 8 & 5.75 & 7 \\
R & 19.75 & 9 & 11.91 & 8 \\
CR & 29.50 & 10 & 24.41 & 11 \\
ST & 34.58 & 11 & 12.83 & 9 \\
\hline
\end{tabular}




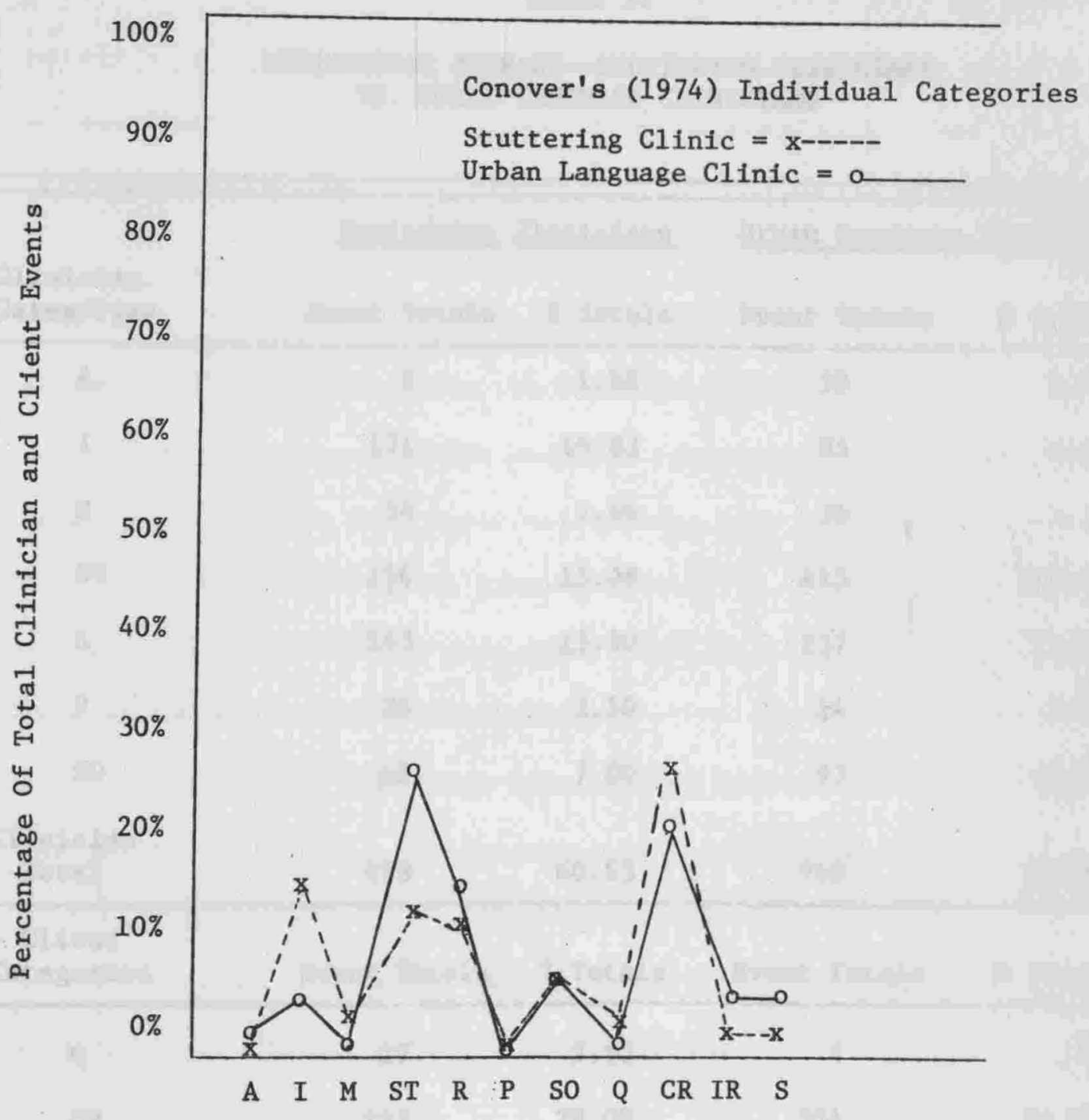

Figure 1. Graph of category percentages for Stuttering C1inic and Urban Language Clinic. 
TABLE II

INTERACTION SUMMARY--STUTTERING CLINICIANS

VS. URBAN LANGUAGE CLINICIANS

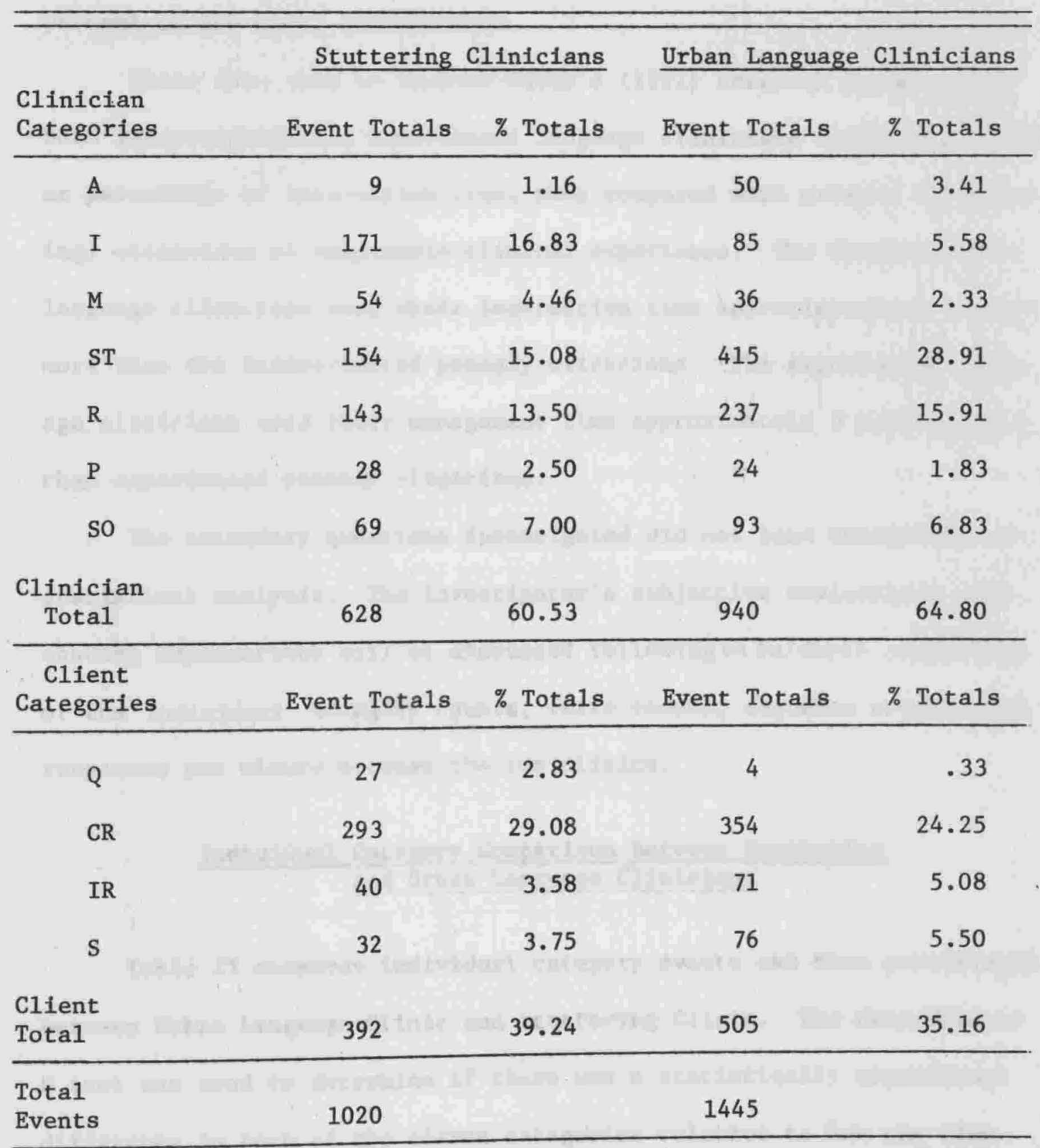


clinician interactions for the two clinics differed only by approximately 4 percent with the Stuttering clinicians utilizing 60.53 percent of the total interactions and the Urban Language clinicians using 64.80 percent of the total interactions.

These data tend to support 01sen's (1972) research which showed both inexperienced and experienced language clinicians utilized a greater percentage of interaction time, when compared with prosody (stuttering) clinicians of comparable clinical experience. The inexperienced language clinicians used their interaction time approximately 5 percent more than the inexperienced prosody clinicians. The experienced language clinicians used their management time approximately 3 percent more than experienced prosody clinicians.

The secondary questions investigated did not lend themselves to statistical analysis. The investigator's subjective evaluations with ensuing implications will be discussed following an in/depth comparison of the individual category counts, ratio counts, sequence counts, and responses per minute between the two clinics.

\section{Individual Category Comparison Between Stuttering And Urban Language Clinicians}

Table II compares individual category events and mean percentages between Urban Language Clinic and Stuttering C1inic. The Mann-Whitney $\mathrm{U}$ test was used to determine if there was a statistically significant difference in each of the eleven categories relative to how the time was used in Urban Language Clinic when compared with Stuttering Clinic. Table III 1ists, by category, the probability and level of significance, if applicable, for both clinics. 
TABLE III

MANN-WHITNEY U TEST OF INDIVIDUAL CATEGORIES

\begin{tabular}{ccc} 
Category & $\alpha$ for two-tailed test & Level of \\
\hline A & .0286 & .05 \\
I & .1142 & NS \\
M & .4858 & NS \\
ST & .0286 & .05 \\
R & .0286 & .05 \\
P & .8858 & NS \\
So & .3428 & NS \\
Q & .0286 & .05 \\
CR & .3428 & NS \\
IR & .0286 & .05 \\
S & .0002 & NS \\
\hline
\end{tabular}


Authority (Category A)

Authority was used more often during Urban Language remediation (3.41 percent) than during Stuttering management ( 1.16 percent). These data indicate a statistically significant difference at the .05 level of confidence. It appears, to this experimenter, the clinicians in Urban Language Clinic utilized this category more frequently because interactions were with pre-school children rather than with the adolescents or adults who comprised Stuttering Clinic.

Information (Category I)

Information was utilized more by Stuttering clinicians (16.83 percent) than Urban Language clinicians (5.58 percent). Although the percentages indicate the Stuttering clinicians provided approximately three times more verbal information to their clients than Urban Language clinicians, the Mann-Whitney U statistic did not show this to be significantly different at the .05 confidence level. This result 1 ikely is due to the ordering or ranking of the observations, without consideration of the magnitude of the numerical differences which is inherent in the MannWhitney U statistic. The numerical range for the Urban Language clinicians was a low mean of 1.66 with the highest mean being 10.66 . The Stuttering clinicians lowest mean was 9.66 and the highest mean was 24.66. These data differ from 01sen's (1972) results for the EXPLAIN/ DESCRIBE category. (This investigator assumes the EXPLAIN/DESCRIBE and INFORMATION categories to be comparable.) Olsen reported inexperienced language clinicians and prosody clinicians used the EXPLAIN/ DESCRIBE cateogry 24.88 percent and 24.98 percent of their clinical time, respectively. In addition, the same study revealed a high positive 
correlation between experienced language clinicians and prosody clinicians, with 25.88 percent and 26.59 percent of their clinical management time being recorded, as EXPLAIN/DESCRIBE.

It seems, to this investigator, there may be several reasons explaining the discrepancy between the use of the INFORMATION category by the clinicians in the two clinics involved in this project. One reason may be the clinicians in Stuttering Clinic found it more advantageous to explain and provide background information concerning the fluency program since they were dealing with adolescents and adults. In other words providing more information may have facilitated remediation with an adult population. Another explanation may be these stuttering clinicians were providing too much information. The clinicians in Urban Language were interacting with children, this in itself may explain why they did not spend more time providing their clients with explainations or background information. The pre-school children in this clinic, most likely, could not retain large quantities of verbal input. Instead, it seems more pragmatic for clinicians interacting with children to shape the desired behavior through models, stimuli, and positive reinforcement. Table II indicates the Urban Language clinicians did use both the STIMULUS (S) and REWARD (R) categories more frequently than the stuttering clinicians, although they used the MODEL (M) category less often.

\section{Stimulus (Category ST)}

Stimulus was used to a greater extent in Urban Language treatment (28.91 percent) than in Stuttering remediation (19.08 percent). These data indicate a statistically significant difference at the .05 level 
of confidence. This result supports 01sen's (1972) research which indicated inexperienced language clinicians used category 14, AUDITORY-VISUAL MODELS (5.62 percent) much more than prosody clinicians (.49 percent). Both category 13 (VISUAL-MODELS and category 14 (AUDITORY-VISUAL MODELS), were used more by experienced language clinicians (.71 percent and 9.63 percent) than prosody clinicians (.05 percent and 3.61 percent). This investigator made the assumption that both category 13 and category 14 were comparable to Conover's (1974) STIMULUS category which includes both auditory and visual stimuli. It appears, in both 01sen's study and the present clinical project, the stimulus categories were used more frequently by language clinicians than prosody clinicians. Olsen explained the discrepancy by stating, "Modeling categories were apparently considered more useful for giving information to the client in language therapy than in prosody therapy." The data from the present clinical research project indicates there may be another explanation. The percentage of clinical time used by Urban Language clinicians to provide stimuli is approximately 44 percent more than the time spent by Stuttering clinicians. The data also revealed the total of correct responses plus incorrect responses by Stuttering clients is 3.33 percent greater than the total of correct and incorrect responses by Urban Language clients (Refer to Table II). The Stuttering clinicians, thus, used fewer stimuli and yet elicited a greater number of responses. This may suggest the Urban Language clinicians were giving more than one stimulus to elicit a response. Another possible explanation is the nature of the remediation techniques used in the two clinics. The remediation program employed at Portland State University to ameliorate stuttering disorders is "Modification of Stuttering Through a Series of Discrimination Tasks" to 
obtain fluency (Casteel, 1974). Briefly, this program involves the client learning to speak in a different way by modifying various parameters of speech. It is a four-stage management program during which a client must pass a set of criteria in each stage before progressing to the next stage. These "criteria checks" are obtained during monologue, dialogue, and conversational speech of the client. The clinicians shape their client's speech, for the most part, during running speech rather than during one-word responses. The clinicians in the present clinical research and design project would frequently utter one stimulus, e.g., "I want you to tell me about what you did today", and modify the speech production of their clients' during the ensuing monologue, by using positive reinforcement.

The remediation methods utilized by clinicians interacting with children in Urban Language Clinic also consisted of operant conditioning techniques, but were applied in a different way. The client's desired response was often a one-word utterance. This is due to the nature of the management program which was directed at working on readiness skills such as, concept development of colors, numbers, prepositions, and body parts. It often was not necessary for a client to respond in a complete sentence. This factor alone necessitates repeated verbal or non-verbal stimuli by the clinician at a high-paced rate, to insure good attending behavior and numerous responses, in a short period of time. Since preschool children cannot retain large quantities of verbal information, generally the stimuli were short one-word or several word utterences, which changed frequently.

These factors may suggest why the STIMULUS (ST) category was used more frequently in Urban Language Clinic which was comprised of children, 
rather than with the adolescents and the adults in Stuttering Clinic. It appears the age of the client is an important factor which in turn affects the remediation techniques used, and also reflects how the clinicians use their management time.

\section{$\underline{\text { Reward (Category R) }}$}

Reward was used more in Urban Language Remediation (19.9 percent) than in Stuttering treatment (13.50 percent). According to the MannWhitney $U$ statistic, this difference is significant at the .05 confidence level. The result does not support 01sen's (1972) study in which the present investigator has assumed the GOOD EVALUATIVES categories to be comparable to Conover's (1974) REWARD category. 0lsen's research reported tangible GOOD EVALUATIVES were used more by inexperienced language clinicians ( .51 percent) than inexperienced prosody clinicians $(.05$ percent). In contrast, both social-verbal and social-nonverbal GOOD EVALUATIVES were utilized more in prosody remediation (13.71 percent and 4.00 percent) than language treatment (11.35 percent and 1.74 percent). 01sen's data revealed similar findings for the experienced prosody and language clinicians. That is, both social-verbal and social-nonverbal GOOD EVALUATIVES were used more in prosody treatment (15.32 percent and 1. 33 percent). 01sen (1972) suggested tangible reinforcers such as cereal and M\&M's were used more in language treatment because the c1ients were children. The verbal and nonverbal reinforcers were used more frequently with adult prosody clients; although more abstract than tangible reinforcers, these intangible reinforcers have been sufficient cues to the clients that their responses were acceptable to their clinicians. 01sen (1972) further stated, 
Although the relative ease of using these categories (social-verbal and social-nonverbal) for adults rather than GOOD EVALUATIVES (tangible) can be readily appreciated there still appears to be an underlying philosophy by prosody clinicians to structure therapy so that there will be a higher percentage of correct responses on the part of the client.

The present clinical project did not support 01sen's findings which indicated prosody clinicians utilized more positive reinforcement, specifically, intangible reinforcers. The present data did support 01sen's contention that a higher percentage of correct responses occurred in stuttering remediation than language treatment; the stuttering clients uttered correct responses 29.08 percent of the time while the language clients percentage of correct responses was 24.25 percent. The difference between the two settings is not statistically significant, but worth noting.

There appear to be a number of reasons explaining why the present research project did not support 0lsen's (1972) data regarding positive reinforcement. First, the nature of the two interaction analysis systems used in both studies may, in part, explain the discrepancy. In the present clinical research project the REWARD category represented both tangible and intangible positive reinforcers, and, in addition, both socialverbal and social-nonverbal positive reinforcers. If this investigator had used the same interaction analysis system as was utilized in 0lsen's (1972) study, a more precise categorical comparison would have been possible. Secondly, the training and philosophical redemiational techniques used by the clinicians in the two studies may explain, in part, the deviation in results for the positive reinforcement categories. In regard to the present research, it appeared to this investigator, the clinicians in Stuttering Clinic used the INFORMATION category (I) more frequently, 
to provide feedback rather than utilizing the REWARD category, to shape the desired response. Perhaps the stuttering clinicians found it useful to explain "why" they were saying "good". Age of the clients may be an explanation for the discrepancy between the Urban Language clinicians and Stuttering clinicians use of the REWARD category. The Urban Language clinicians may have responsed to correct responses more frequently with positive reinforcement (REWARD) because it was the most successful method of attaining the target goal, and maintaining their clients attention. The preschool children in Urban Language clinic, most likely, would not have comprehended additional information or modified their behavior due to explainations. Short, enthusiastic, often one-word utterences of positive reinforcement appeared to shape the preschoolers behavior most successful1y.

The remaining clinician categories, MODEL, PUNISHMENT, and SOCIAL showed no statistically significant difference or percentage differences between Urban Language clinicians and Stuttering clinicians.

\section{Individual Category Comparisons Between Stuttering} Clients And Urban Language Clients

\section{Question (Category Q)}

Question was used more by Stuttering clients (2.83 percent) than Urban Language clients (.33 percent). These data indicate a statistically significant difference at the .05 level of confidence. The adolescents and adults in Stuttering Clinic not only asked questions, but made self-evaluations regarding the correctness or incorrectness of their responses. Since the clients' self-evaluations were often spontaneous, not following a stimulus (ST) from the clinician, the 
investigator did not consider them as either correct or incorrect responses when recording events. Due to the confines of the Conover Analysis System, these self-evaluations were recorded under the QUESTION category. Age of the clients could also have been a factor as adults were given more opportunities to question whereas pre-schoolers were not encouraged to do so. Further discussion regarding the stuttering clients self-evaluations will be examined as a partial response to the final question investigated by this clinical project.

\section{Incorrect Response (Category IR)}

Incorrect response was used more by Urban Language clients $(5.08$ percent) than Stuttering clients (3.58 percent). According to the MannWhitney U statistic, this was significant at the .05 level of confidence. A higher degree of incorrect responses in Urban Language clinic may be explained in several ways. It seems, to this investigator, the intrinsic motivation of the clients might be reflected by the correctness, or lack of it, in their responses. It appeared the adult clients in Stuttering clinic were highly motivated to work on improving their fluency. The children in Urban Language Clinic, when provided with a "powerful" tangible or intangible reinforcer, appeared to perform with a higher level of correct responses. However, when they were not presented with a "powerful" reinforcer, they appeared to interact with fewer correct responses. A final conjecture, suggesting a possible explanation for the higher percentage of incorrect responses in Urban Language clinic, is the nature of remediation techniques used with each disorder. It seems, to this investigator, the responses in Urban Language clinic were either "black or white", wrong or right. In other words, naming the color blue 
or rote counting to five, is correct by giving only that specific response. The fluency treatment employed by the Stuttering clinicians (Casteel, 1974), in contrast, involves a great deal of shaping. In the process of reaching the target goal, what inevitably would be an incorrect response is accepted as a correct response. It appears, clinical supervisors viewing remediation of any disorder need to be aware of the shaping techniques employed in order to be cognizant of whether the clinician is accepting an incorrect response, or shaping a desired one.

The remaining client categories CORRECT RESPONSE and SOCIAL, did not differ significantly statistically between the two clients.

\section{Difference Analysis By Interaction Ratios}

The interaction ratios utilize the individual categories to summarize the data in a different manner. They tend to reflect, more than the individual categories, how the clinicians interacted during remediation (01sen, 1972).

Table IV compares ratio responses of Urban Language clinicians and Stuttering clinicians. See Appendix I for a description of the ratios. The good evaluative ratio and bad evaluative ratio were higher for Urban Language remediation ( 49.55 percent and 26.50 percent) than for stuttering treatment (28.00 percent and 15.75 percent). These data support 01sen's (1972) research in which both the good evaluative ratio and bad evaluative ratio were higher for inexperienced language clinicians ( 52.48 percent and 30.58 percent) than for inexperienced prosody clinicians ( 45.46 percent and 25.93 percent).

The present research, however, does not support 01sen's data with experienced clinicians. He reported although there were fewer incorrect 
TABLE IV

SEQUENCE SUMMARY--STUTTERING CLINICIANS

VS. URBAN LANGUAGE CLINICIANS

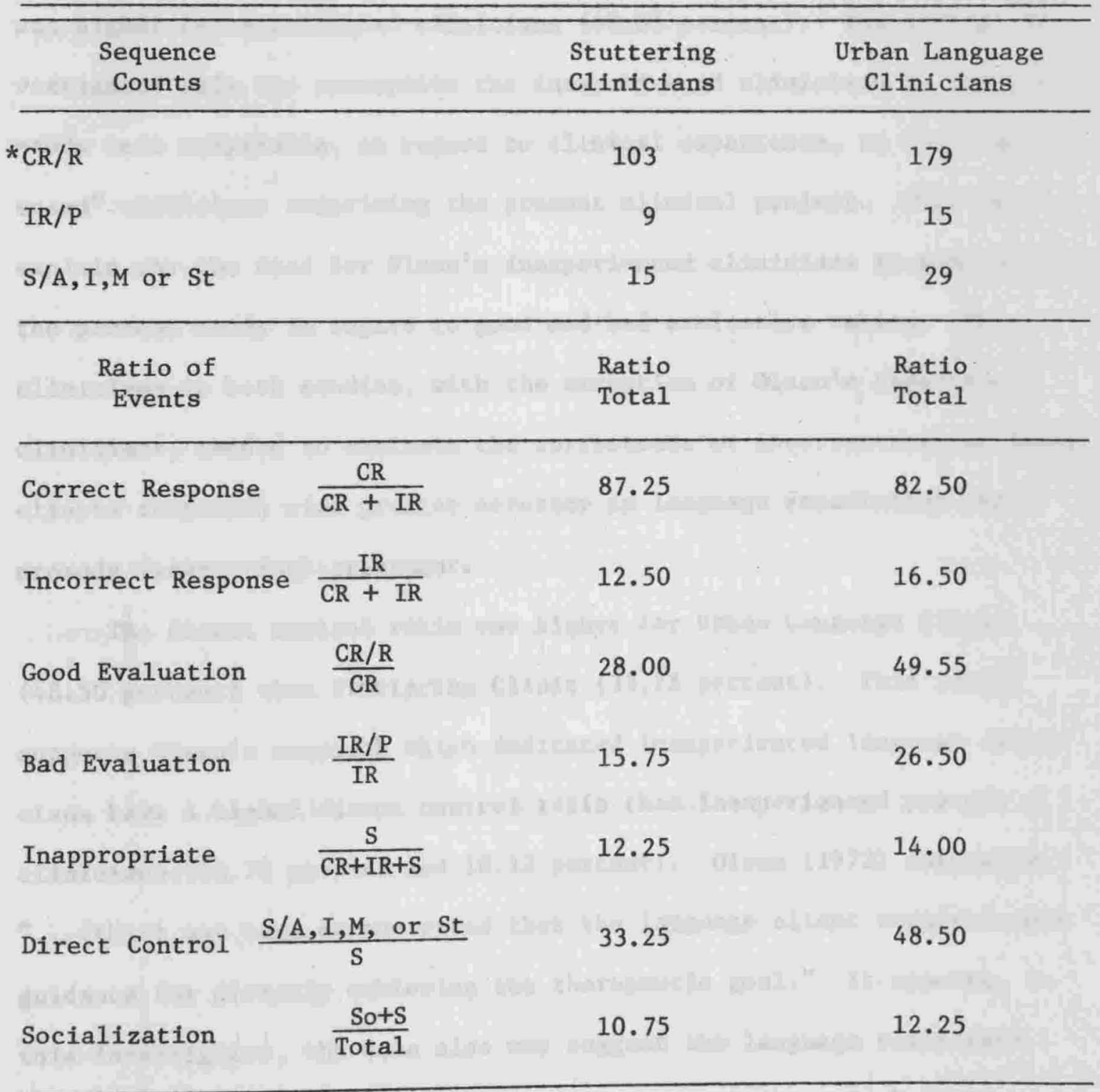

*"/" - a slash indicates the first response (CR) immediately followed by a second response ( $R$ ) 
responses for prosody management than for language treatment, the bad evaluative ratio was higher for prosody management ( 47.69 percent) than for language remediation (37.98 percent). The good evaluative ratio also was higher for experienced clinicians (48.03 percent). The present investigator made the assumption the inexperienced clinicians in 01sen's study were comparable, in regard to clinical experience, to the "experienced" clinicians comprising the present clinical project. This may explain why the data for 01sen's inexperienced clinicians is similar to the present study in regard to good and bad evaluative ratios. The clinicians in both studies, with the exception of 0lsen's experienced clinicians, tended to evaluate the correctness or incorrectness of their clients responses with greater accuracy in language remediation than prosody (stuttering) treatment.

The direct control ratio was higher for Urban Language Clinic (48.50 percent) than Stuttering Clinic (33.25 percent). This result supports 01sen's research which indicated inexperienced language clinicians have a higher direct control ratio than inexperienced prosody clinicians (63.72 percent and 18.12 percent). 0lsen (1972) suggested, "...(this) may have demonstrated that the language client required more guidance for directly achieving the therapeutic goal." It appears, to this investigator, the data also may suggest the language clinicians were more adept at bringing an off-task client, back on task again. Again, the age of the client is probably an important factor. It appears pre-schoolers would be more apt to engage in off-task behavior than adolescents or adults.

The remaining ratio of events listed in Table IV did not vary by more than approximately 4 percent, indicating a high similarity in the 
interactions of clinicians/clients in both clinics.

Sequences of interaction patterns, and their results are listed in Table IV. The three sequence patterns noted can provide valuable information regarding a remediation session. The "/" indicates the first interaction was immediately followed by the second, e.g., "CR/R", means a CORRECT RESPONSE immediately followed by a REWARD. The results indicated Urban Language clinicians more of ten responded to a correct response with positive reinforcment, to an incorrect response with punishment, and more frequently brought an "off-task" client back on task by direct control (A, I, M, or St). Again it appears age may be a factor when looking at these results. Children may require more positive reinforcement, at more frequent intervals, or for a longer duration, than adults. It is more likely the clinicians in Urban Language Clinic had to respond, via direct control, to inappropriate verbal or non-verbal behavior of their clients, than the clinicians interacting with adults in Stuttering Clinic.

As indicated in Table II the total number of events was greater for Urban Language Clinic than for Stuttering Clinic. The average number of responses for Urban Language Clinic was also greater than Stuttering Clinic. The mean number of responses, per minute, for Urban Language clinicians was 7.08 , and for Stuttering clinicians it was 5.70 responses per minute. These data may be due to the remediation techniques utilized, which indicated the Urban Language clinicians often desired one-word responses, used short stimuli, and employed a high-paced rate during management. 


\section{The Effectiveness of The Conover Analysis System}

The second question:investigated in this clinical research and demonstration project was: Is the Conover Analysis System effective as an objective method of observing the interaction of clinicians and their clients in each of the two different clinical settings? This question did not lend itself to statistical analysis. This investigator's subjective evaluation served as the basis for discussion of this question.

It appeared, to this investigator, the Conover Analysis System (Conover, 1974) was a good objective method for evaluating the interactions of clinicians and their clients in Urban Language Clinic. The investigator did not experience, during any observation in Urban Language Clinic, an instance when a clinician or client interacted with a response which could not be categorized under the Conover Analysis System:

It seems, according to the data revealed in the present clinical project and this investigator's subjective evaluation, the Conover could provide clinical supervisors and/or clinicians with invaluable information regarding clinical remediation. The clinicians not only could compute percentages and ratios to determine how they were using their clinical time, but in addition, they could visually see sequential patterns of interaction. If the clinical supervisor and/or clinician recorded data from a "Conover," weekly, on a form similar to Figure 2 the clinicians could actually track their own interactions and possibly determine what areas of remediation need changes. Perhaps, this record form could aid the clinical supervisor in determining clinicians' management skills, rates of improvement, and 
Clinician:

Term:
Client:

Type of Client:

\begin{tabular}{|c|c|c|c|c|c|c|}
\hline \multirow[b]{2}{*}{ Category \& Ratio } & Raw & te By & & \multicolumn{3}{|c|}{ Percentage By Date } \\
\hline & $2 / 14$ & $2 / 21$ & $2 / 28$ & $2 / 14$ & $2 / 21$ & $2 / 28$ \\
\hline 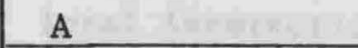 & 0 & 0 & 0 & 0 & 0 & 0. \\
\hline I & 5 & 14 & 10 & $12 \%$ & $28 \%$ & $20 \%$ \\
\hline $\mathrm{M}$ & 8 & 4 & 0 & $19 \%$ & $8 \%$ & 0 \\
\hline ST & 16 & 13 & 21 & $37 \%$ & $26 \%$ & $43 \%$ \\
\hline $\mathrm{R}$ & 9 & 4 & 8 & $20 \%$ & $8 \%$ & $16 \%$ \\
\hline $\mathrm{P}$ & 0 & 2 & 1 & 0 & $4 \%$ & $2 \%$ \\
\hline So & 5 & 13 & 9 & $12 \%$ & $26 \%$ & $19 \%$ \\
\hline Q & 0 & 4 & 0 & 0 & $14 \%$ & 0 \\
\hline $\mathrm{CR}$ & 26 & 15 & 36 & $72 \%$ & $50 \%$ & $92 \%$ \\
\hline IR & 6 & 6 & 3 & $17 \%$ & $20 \%$ & $8 \%$ \\
\hline $\mathrm{S}$ & 4 & 5 & 0 & $11 \%$ & $16 \%$ & 0 \\
\hline $\begin{array}{c}\text { Clinician } \\
\text { Total } \%\end{array}$ & 43 & 50 & 49 & $100 \%$ & $100 \%$ & $100 \%$ \\
\hline $\begin{array}{l}\text { Client } \\
\text { Total \% }\end{array}$ & 36 & 30 & 39 & $100 \%$ & $100 \%$ & $100 \%$ \\
\hline
\end{tabular}

\begin{tabular}{|lc|c|c|c|c|c|}
\hline$\frac{\mathrm{CR}}{\mathrm{CR}, \mathrm{IR}}$ & $26 / 32$ & $15 / 21$ & $36 / 39$ & .81 & .71 & .92 \\
\hline$\frac{\mathrm{IR}}{\mathrm{CR}, \mathrm{IR}}$ & $6 / 32$ & $6 / 21$ & $3 / 39$ & .19 & .29 & .08 \\
\hline$\frac{\mathrm{CR} / \mathrm{PR}}{\mathrm{CR}}$ & $7 / 26$ & $3 / 15$ & $6 / 36$ & .27 & .20 & .16 \\
\hline$\frac{\mathrm{IR} / \mathrm{P}}{\mathrm{IR}}$ & $0 / 6$ & $0 / 6$ & $0 / 3$ & 0 & 0 & 0 \\
\hline$\frac{\mathrm{S}}{\mathrm{CR}, \mathrm{IR}, \mathrm{S}}$ & $4 / 36$ & $5 / 26$ & $0 / 39$ & .11 & .19 & 0 \\
\hline $\begin{array}{l}\mathrm{S} / \mathrm{A}, \mathrm{I}, \mathrm{M}, \mathrm{St} \\
\mathrm{S}\end{array}$ & $2 / 4$ & $4 / 5$ & $0 / 0$ & .50 & .80 & 0 \\
\hline $\begin{array}{c}\text { So+S } \\
\text { Total }\end{array}$ & $9 / 79$ & $18 / 80$ & $9 / 88$ & .12 & .23 & .10 \\
\hline $\begin{array}{c}\text { Total \# } \\
\text { of Events }\end{array}$ & 79 & 80 & 88 & & & \\
\hline $\begin{array}{l}\text { \# Responses/ } \\
\text { Minute }\end{array}$ & 6.4 & 6.2 & 7.8 & & & \\
\hline
\end{tabular}

Figure 2. Adaptation of Gordon's (1975) Conover Analysis System Data Sheet by Teresa Carnese (1977). 
possibly, grades for the term.

It appeared, to this investigator, all of the Conover Analysis System's categories were useful and necessary for recording the behavioral interactions of clinicians/clients in Stuttering Clinic. In addition, though, the investigator would include an additional category, SELF EVALUATION, to insure the adequacy of this analysis system when recording events for adult stuttering clients at Portland State University.

\section{Modifications of The Conover Analysis System}

The third question investigated in this clinical research and demonstration project was: Are there modifications on the Conover Analysis System which would facilitate the recording of clinician-client interaction in either of the clinical settings? The investigator stated in Chapter III, page 26, self-evaluations made by adult stuttering clients were recorded under the QUESTION (Q) category because the Conover Analysis System (1974) does not include a category for that type of client response. This investigator recommends inclusion of a SELFEVALUATION (SE) category for responses which were not correct or incorrect responses, or questions from the client. More specifically, any response which indicates the client is evaluating the correctness or incorrectness of a response would be recorded as a SELF-EVALUATION (SE). It does not appear, to this investigator, it is necessary to specify whether the client made a correct self-evaluation regarding a previous correct or incorrect response. It seems the sequence of interaction, following the $\mathrm{SE}$, between the cliniclan and the client might indicate the correctness of the response. For example, if the SE was followed 
by a REWARD ( $R$ ) the assumption could be made it was a correct evaluation. However, if the SE is followed by a PUNISHMENT (P), this may indicate the clinician disagrees with the clients evaluation. In addition, if a $\mathrm{SE}$ is followed by a STIMULUS (ST) it might be conjectured the clinician desired a rationale for the clients self-evaluation. The sequential client/clinician interaction following the ST may suggest whether, according to the clinician, the client gave a correct response.

\section{Additional Information}

One of the clinicians participating in this clinical project was enrolled in both Urban Language Clinic and Stuttering Clinic. The Spearman Rank-Order Correlation Coefficient (RHO) was used to determine whether there was a significant difference, overall, in the subject's use of clinical management time in the two settings. The data resulted in a correlation coefficient of .10 which indicates a minimal correlation between the subject's overall use of clinical management time.

In summary, the clinicians overall utilized their clinical management time, in a similar manner, in both Urban Language Clinic and Stuttering Clinic. An individual category and ratio analysis did indicate statistically significant differences between the two clinics. A comparison of one subject's interactions, in both clinics, indicated very little similarity in use of clinical remediaiton time. The Conover Analysis Systems (Conover, 1974) was an effective means of recording clinician/client interactions in Urban Language Clinic. It appears if the category SELF-EVALUATION (SE) is included when observing adult Stuttering remediation, the Conover Analysis System would be an effective 
method of recording events in Stuttering Clinic.

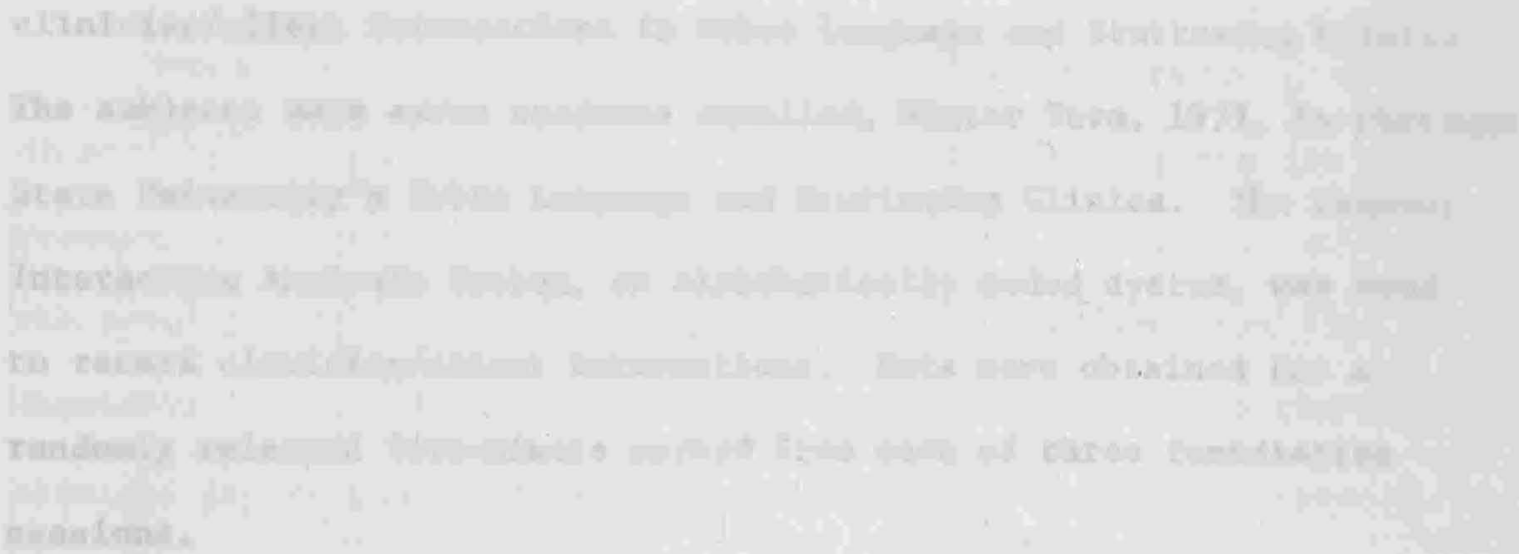

-

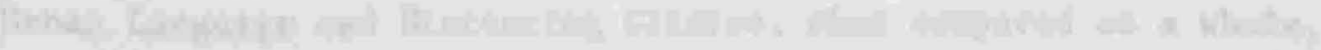

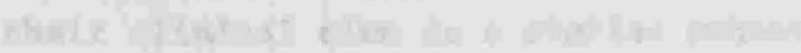

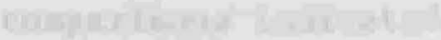

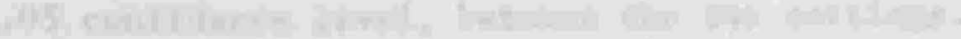

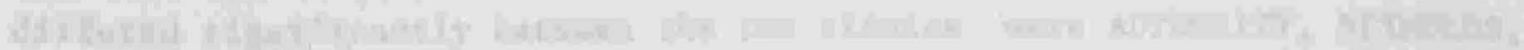

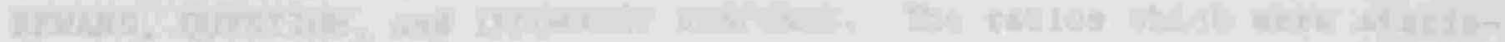

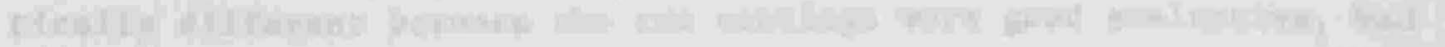

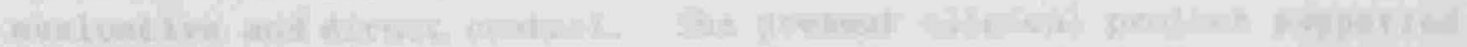

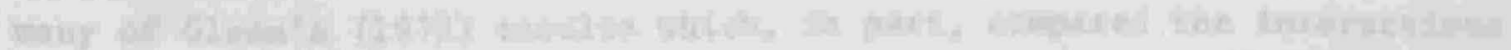

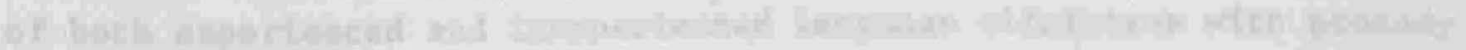

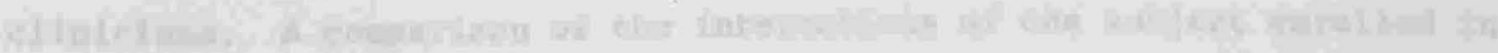




\section{CHAPTER V}

\section{SUMMARY AND IMPLICATIONS}

\section{$\underline{\text { Summary }}$}

This clinical research and demonstration project compared the clinician/client interactions in Urban Language and Stuttering Clinics. The subjects were seven students enrolled, Winter Term, 1977, in Portland State University's Urban Language and Stuttering Clinics. The Conover Interaction Analysis System, an alphabetically coded system, was used to record clinician/client interactions. Data were obtained for a randomly selected five-minute period from each of three remediation sessions.

Results of this clinical project indicate clinicians in both Urban Language and Stuttering Clinics, when compared as a whole, utilize their clinical time in a similar manner. Individual category and ratio comparisons indicated some statistically significant differences at the .05 confidence level, between the two settings. The categories which differed significantly between the two clinics were AUTHORITY, STIMULUS, REWARD, QUESTION, and INCORRECT RESPONSE. The ratios which were statistically different between the two settings were good evaluative, bad evaluative and direct control. The present clinical project supported many of 0lsen's (1972) results which, in part, compared the interactions of both experienced and inexperienced language clinicians with prosody clinicians. A comparison of the interactions of one subject enrolled in 
both clinics, indicated little similarity in the use of clinical management time. The Conover Analysis System appeared to be an effective method for observing and recording the interactions of clinicians/clients in Urban Language Clinic. It appears, a category for self-evaluation is needed when recording the behavioral events of clinicians/clients in Stuttering Clinic.

\section{Implications}

There are a number of implications for further research, as indicated by this clinical project. One would be to replicate the present research and demonstration project, with a larger sample, to substantiate the results. Another would be to record events for more than just two disorders, as did 01sen (1972), and compare the results with the present clinical project, and substantiate the remainder of 01 sen's $^{2}$ research.

Further research, utilizing a larger sample. where all subjects are enrolled in clinical remediation in two or more different clinics, is necessary. Research involving clients of various age levels, demonstrating the same disorder would be beneficial. It seems, research in these areas would help determine if the differences in the use of clinical time are factors of the communicative disorder or age of the clients.

Finally, a comparison of different subjects, or the same subject, utilizing two different philosophical remediation techniques, e.g., behavior modification and psychotherapy, with the same disorder would be interesting. Perhaps, the results would suggest which remediation technique facilitates and maintains the target goal most effectively. 


\section{SELECTED BIBLIOGRAPHY}

American Speech and Hearing Association. Minimum requirements for ETB Accreditation. ASHA, 18, 110-113 (1976).

Amidon, E. J., and Flanders, N., Interaction analysis as a feedback system. In E. J. Amidon and E. G. Hough (eds.), Interactions Analysis: Theory, Research and Application. Reading, Mass.: AddisonWesley (1967).

Amidon, E. J., and Hough, E. G. Interaction Analysis: Theory, Research and Application. Reading Mass.: Addison-Wesley (1967).

Anderson, J. L., Supervision of school speech, hearing, and language programs - An emerging role, ASHA, 16. 7-10 (1974).

Boone, D. R., and Goldberg, A. An Experimental Study of the Clinical Acquisition of Behavioral Principles by Videotape Self-Confrontation. Final report, Project No. 4071, Grant No. OEG 8-071319-2814, U.S. Department of Health, Education and Welfare, Division of Research, Bureau of Education for the Handicapped, Office of Education (1969).

Boone, D. R., and Prescott, T., Content and sequence analysis. ASHA, 14, 58-62 (1972).

Boone, D. R., and Stech, E. L., The Development of Clinical Skills in Speech Pathology by Audiotape and Videotape Self-Confrontation. Final Report, Project No. 1381, Grant No. OEG-9-071318-2814, U.S. Department of Health, Education and Welfare, Division of Research, Bureau of Education for the Handicapped, Office of Education (1970).

Brown, E. L., A university's approach to improving supervision. ASHA, 9, 476-479 (1967).

Brooks, S. J., and Hannah, E. P. A tool for clinical supervision. J. Speech and Hearing Disorders, 31, 383-387 (1966).

Butler, K. W. Videotaped self-confrontation. LSHSS, 4:3, 162-167 (1974).

Castee1, R. L. The Modification of Stuttering Through a Series of Discrimination Tasks. Paper presented at the ASHA Convention, November 6, 1974. (Jas Vegas)

Conover, H. Conover Analysis System. Paper presented at the ASHA Convention, Las Vegas (November, 1974). 
Culatta, R., Colucci, S., and Wiggins, E. Clinical supervisors and trainees: Two views of a process. ASHA, 17 (3), 152-157 (1975).

Diedrich, W. M. Use of videotape in teaching clinical skills. Volta Rev., 644-647 (1966).

Downie, N. M., and Heath, R. W. Basic Statistical Methods. Harper \& Brothers, Publishers, New York (1959).

Geoffrey, v. C. Report on Supervisory Practices in Speech and Hearing. Unpublished report, University of Maryland (November, 1973).

Golper, L. C. The Efficacy of Teaching Interaction Analysis to Students in Speech Pathology. Master's substantial paper, Portland State University (1976).

Gordon, M. Conover Analysis System Session Scoring Form. (1975). Unpublished form: Portland, Oregon, Portland State University.

Grove, T. Personal communication (1976).

Halfond, M. M. Clinical supervision--Stepchild in training. ASHA, 6 . 441-445 (1964).

Haller, R. Supervisor's criteria for evaluation students' performance in clinical observation. ASHA, 9, 479-481 (1967).

Irwin, R. B. and Nickles, A. A. The use of audiovisual films in supervised observation. ASHA, 12, 363-367 (1970).

Jacobson, E. Progressive Relaxation. The University of Chicago Press. Chicago, I1l. (1929).

Johnson, T. S. The Development of a Multi-dimensional Scoring System for Observing the Clinical Process in Speech Pathology. Doctoral Dissertation, University of Kansas (1969).

Klevans, D. R., and Volz, H. B. Development of a clinical evaluation procedure. ASHA, 16, 489-491 (1974).

Kunze, L. Program for training in behavioral observation. ASHA, 9, 473-476 (1967).

McMahon, J. Personal Communication (1977).

Mendenha11, W. Introduction to Probability and Statistics, (Third Edition). Duxbury Press, Belmont California (1971).

Miner, A. Standards for quality supervision of clinical practicum. ASHA, 9, 471-472 (1967). 
01sen, B. D. Comparison of Sequential Interaction Patterns in Therapy of Experienced and Inexperienced Clinicians in the Parameters of Articulation, Delayed Language, Prosody, and Voice Disorders. Unpublished doctoral dissertation: Denver, Co, Univ. of Denver (1970).

Payne, P. D. and Koller, E. E., Teaching and Supervision Student Clinicians Using Closed Circuit Television. Paper presented at ASHA Convention, Las Vegas (1974).

Prescott, T. E. The Development of a methodology for Describing Speech Therapy. Unpublished doctoral dissertation: Denver, Colorado, University of Denver (1970).

Schubert, G. W. Suggested minimal requirement for clinical supervisors. ASHA, $16(6), 305-307$ (1974).

Schubert, G. W. and Laird, B. A. Length of Time Necessary to Obtain a Representative Sample of Clinician-Client Interaction. Paper presented at the ASHA Convention, Las Vegas (1974).

Schubert, G. W., Miner, A. L., and Till, J. A. The Analysis of Behavior of Clinicians (ABC) System. University of North Dakota Press (1973).

Schultz, M. C. An Analysis of Clinical Behavior in Speech and Hearing. Prentice-Hall, Inc. Englewood Cliffs, N.J. (1972).

Stace, A. C. and Drexler, A. B. Special training for supervisors of student clinicians: What private speech and hearing centers do and think about training their supervisors. ASHA, 11, 318-320 (1969).

Stech, E. L. A set of learning theory categories for analyzing the speech therapy situation: A manual for scoring video and audio tapes. Unpublished manuscript, Denver (1969).

Van Riper, C. Supervision of clinical practice. ASHA, 7, 75-77 (1965).

Ward, W. D., and Webster, E. J. The training of clinical personnel: Issues in Conceptualization. ASHA, 7, 38-40 (1965a).

Ward, W. D., and Webster, E. J. The training of clinical personnel: II, A concept of clinical preparation. ASHA, 7, 103-106 (1965b).

Williams, F. Reasoning With Statistics: Simplified Examples in Communications Research. Holt, Rinehart and Winston, Inc., San Francisco (1968).

Withal1, J. The development of a technique for the measurement of social-emotional climate in classrooms. In E. J. Amidon and E. S. Hough (eds,), Interaction Analysis: Theory Research and Application. Reading Mass: Addision-Wesley (1967). 


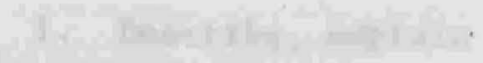

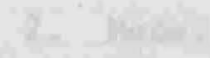

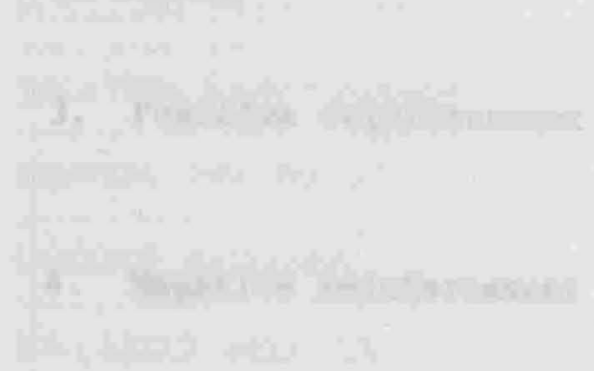

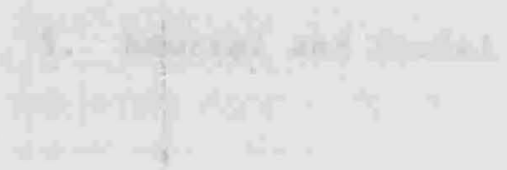

16.

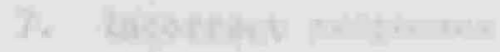

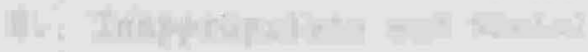

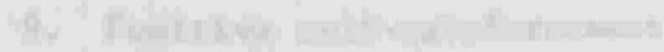

16.

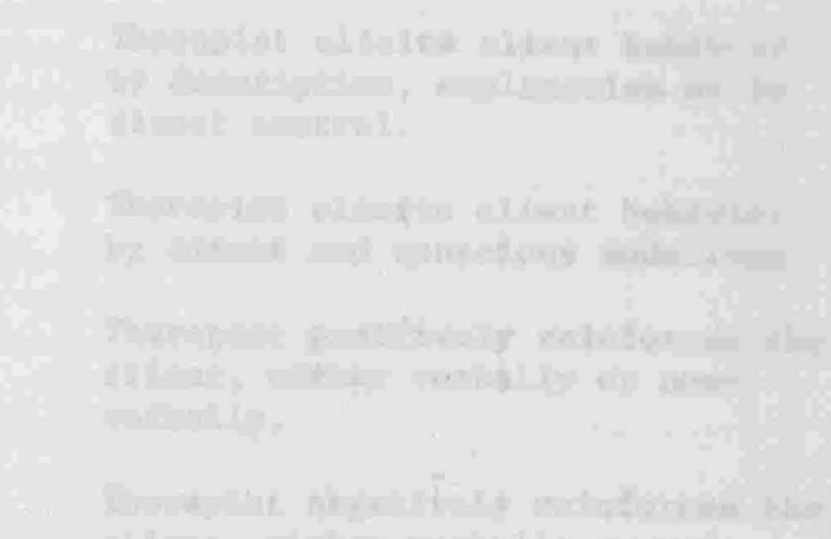

APPENDICES

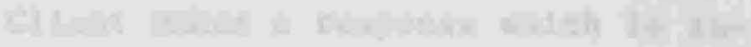

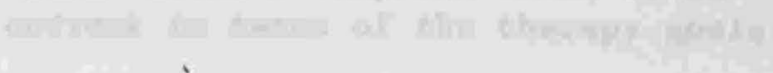

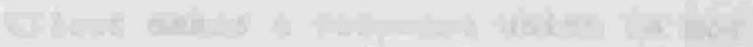

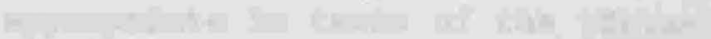
10.5.

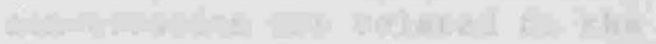

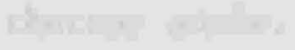

thate

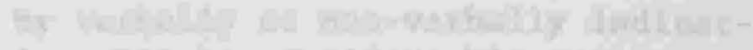

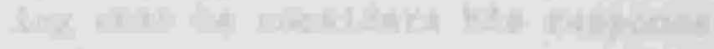
C-

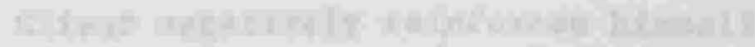

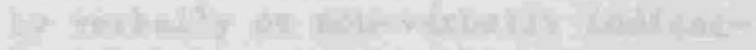

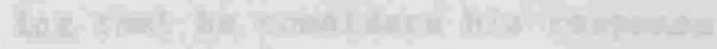

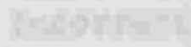


APPENDIX A

\section{STECH 10 CATEGORY INTERACTION ANALYSIS SYSTEM}

1. Describe, explain

2. Mode1

3. Positive reinforcement

4. Negative reinforcement

5. Neutral and Social

6. Correct responses

7. Incorrect responses

8. Inappropriate and Social

9. Positive self-reinforcement

10. Negative self-reinforcement
Therapist elicits client behavior by description, explanation or by direct control.

Therapist elicits client behavior by direct and conscious modelling.

Therapist positively reinforces the client, either verbally or nonverbally.

Therapist negatively reinforces the client, either verbally or nonverba11y.

Therapist engages in activities which do not require client response or which deal with session goals.

Client makes a response which is correct in terms of the therapy goals.

Client makes a response which is incorrect in terms of the therapy goals.

Client makes a response which is not appropriate in terms of the therapist's goals or engages in social conversation not related to the therapy goals.

Client positively reinforces himself by verbally or non-verbally indicating that he considers his response correct.

C1ient negatively reinforces himself by verbally or non-verbally indicating that he considers his response incorrect. 
APPENDIX B

CONTINUOUS LINE RECORDING

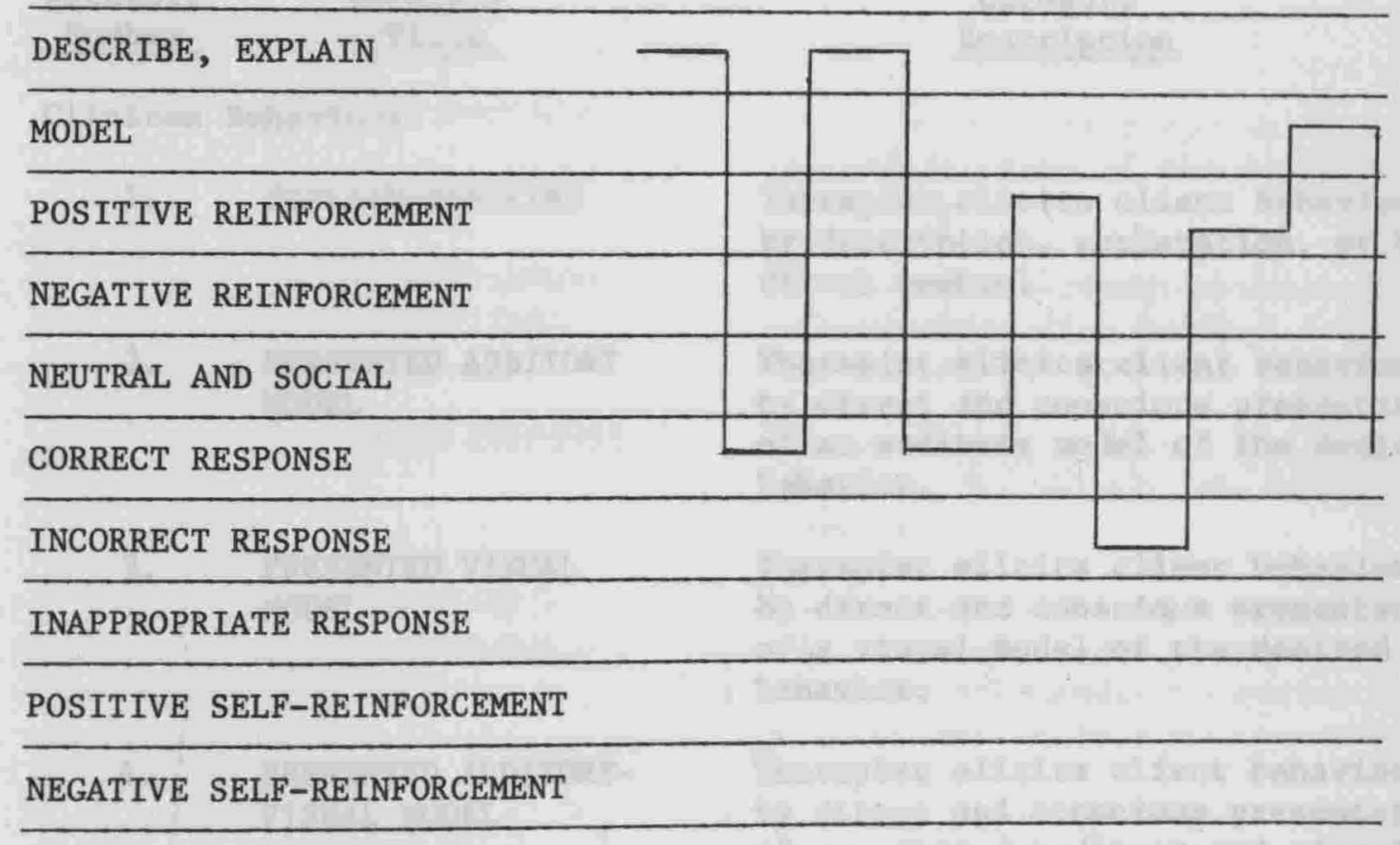




\section{APPENDIX C}

\section{PRESCOTT 19 CATEGORY INTERACTION ANALYSIS SYSTEM}

$\begin{array}{cc}\begin{array}{c}\text { Category } \\ \text { Number }\end{array} & \begin{array}{c}\text { Category } \\ \text { Title }\end{array} \\ \text { Clinican } & \text { Behaviors: } \\ 1 . & \text { EXPLAIN/DESCRIBE } \\ \text { 2. } & \begin{array}{c}\text { PRESENTED AUDITORY } \\ \text { MODEL }\end{array}\end{array}$

3. PRESENTED VISUAL MODEL

4. PRESENTED AUDITORYVISUAL MODEL

5. POSITIVE REINFORCER (TANGIBLE)

6. POSITIVE REINFORCER (SOCIAL-VERBAL)

7. POSITIVE REINFORCER (SOCIAL-NONVERBAL)

8. NO OBSERVABLE REINFORCER

9. NEGATIVE REINFORCER (TANGIBLE)

10. NEGATIVE REINFORCER (SOCIAL-VERBAL)
Category

Description 


\begin{tabular}{cc}
$\begin{array}{c}\text { Category } \\
\text { Number }\end{array}$ & $\begin{array}{c}\text { Category } \\
\text { Title }\end{array}$ \\
\cline { 1 - 2 } 11. & $\begin{array}{c}\text { NEGATIVE REINFORCER } \\
\text { (SOCIAL-NONVERBL) }\end{array}$ \\
12. & NEUTRAL/SOCIAL
\end{tabular}

C1ient Behaviors:

13. CORRECT RESPONSE

14. INCORRECT RESPONSE (APPROXIMATION)

15. INCORRECT RESPONSE

16. INAPPROPRIATE/ SOCIAL RESPONSE

17. POSITIVE SELFREINFORCER

18. NEGATIVE SELFREINFORCER

19. NO RESPONSE

\section{Category \\ Description}

Therapist negatively rewards client behavior by indicating disapproval nonverbally.

Therapist engages in activities which do not require client response or do not deal with the session goals.

Client makes a response which is correct in terms of the stimulus presented.

Client makes a response which is an approximation of a correct response in terms of the stimulus presented.

Client makes a response which is incorrect in terms of the stimulus presented.

Client makes a response which is not appropriate in terms of the stimulus presented or engages in social or behavior not related to the stimulus presented.

Client indicates, verbally or nonverbally, that he considers his response to be correct.

Client indicates, verbally or nonverbally, that he considers his response to be incorrect.

Client does not respond, verbally or nonverbally, to the stimulus presented. 
APPENDIX D

\section{BOONE - PRESCOTT CONTENT AND \\ SEQUENCE ANALYSIS SYSTEM}

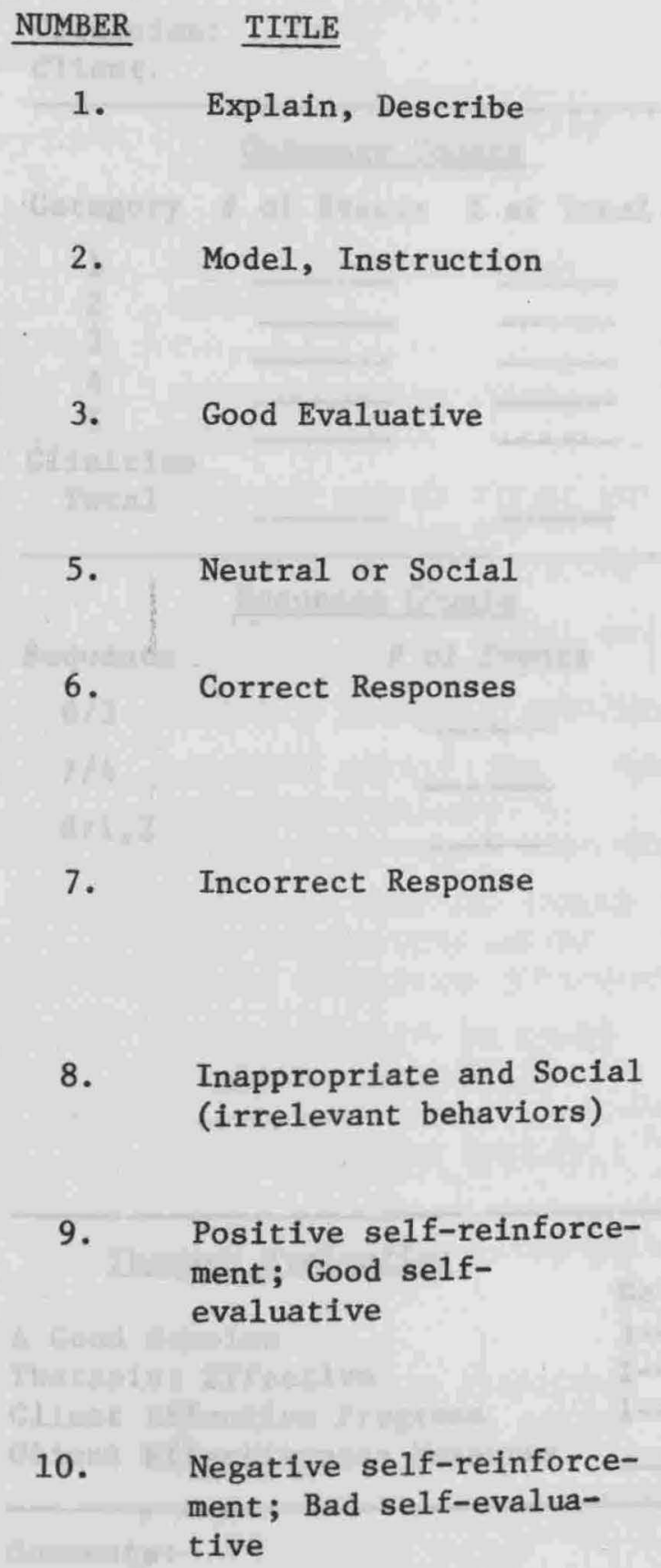

\section{DESCRIPTION}

Clinician describes or explains the specific goals or procedures of the session.

Clinician specifies client behavior by direct modeling or by a specific request.

Clinician evaluates client response and indicates approval verbally or non-verbally.

Clinician engages in behavior that is not management goal oriented.

Client makes a response which is correct in terms of the stated management goals, or the clinician stimulus

Client makes a response that is incorrect according to the stated management goals or clinician request

Client makes a response or engages in social conversation that is not appropriate to the management goals

Client positively reinforces himself (rewards himself in an observable manner) verbally or non-verbally when he considers his response correct

Client negatively reinforces himself (punishes or removes a positive reinforcer) verbally or non-verbally when he considers his response to be incorrect 
APPENDIX E

BOONE-PRESCOTT TEN CATEGORY SPEECH AND

HEARING THERAPY SESSION SCORING FORM

Clinician:

Date:

Client:

\section{Category Counts}

Category \# of Events \% of Total

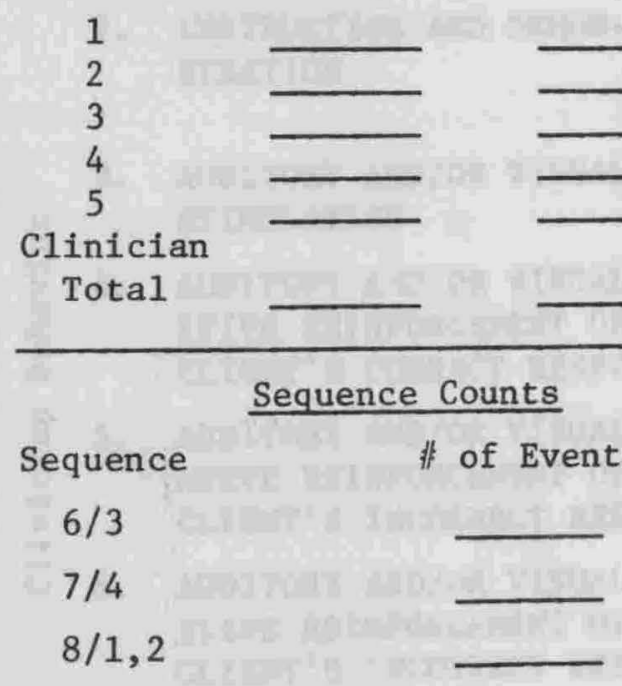

Category \# of Events \% of TOTAL 6
7
8
9
10
Client
Total

\section{Total}

\section{$\underline{\text { Ratio Scoring }}$}

Correct Response $\frac{6}{6,7}=$ Incorrect Response $\frac{7}{6,7}=$ Good Eval Ratio $\frac{6 / 3}{6}=$ Bad Eval Ratio $\frac{7 / 4}{7}=$ Inappro. Response $\frac{8}{6,7,8}=$ Direct Contro1 $\frac{8 / 1,2}{8}=$ Socialization $\frac{5+8}{\text { Total }}=$

\section{Therapy Evaluation}

\section{A Good Session}

Therapist Effective

Client Effective Progress

Client Effectiveness Measures

$$
\begin{aligned}
& \text { No } \\
& 1--2--3--4--5--6--7--8-9 \\
& 1--2--3--4--5--6--7--8-9 \\
& 1--2--3--4--5--6--7--8--9
\end{aligned}
$$




\section{APPENDIX $\mathrm{F}$ \\ ANALYSIS OF BEHAVIOR OF CLINICIANS \\ ABC SYSTEM - SCHUBERT, \\ MINER, TILL}

Category

Definition

1. OBSERVING AND MODIFYING LESSON APPROPRIATELY

Using response or action of the client to adjust goals and/or strategies.

2. INSTRUCTION AND DEMONSTRATION

Process of giving instruction or demonstrating the procedures to be used.

3. AUDITORY AND/OR VISUAL STIMULATION

Questions, cues, and models intended to elicit a response.

4. AUDITORY AND/OR VISUAL POSITIVE REINFORCEMENT OF CLIENT'S CORRECT RESPONSE

5. AUDITORY AND/OR VISUAL NEGATIVE REINFORCEMENT OF CLIENT'S INCORRECT RESPONSE

6. AUDITORY AND/OR VISUAL POSITIVE REINFORCEMENT OF CLIENT'S INCORRECT RESPONSE

Process of giving any positive response to correct client response.

Process of giving any negative response to an incorrect client response.

Process of giving any positive response to an incorrect client response.

7. CLINICIAN RELATING IRRELEVANT INFORMATION AND/OR ASKING IRRELEVANT QUESTIONS

Talking and/or responding in a manner unrelated to changing speech patterns.

8. USING AUTHORITY OR DEMONSTRATING DISAPPROVAL

Changing social behavior for unacceptable to acceptable behavior.

9. CLIENT RESPONDS CORRECTLY

Client responds appropriately, meets expected level.

10. CLIENT RESPONDS INCORRECTLY

Client apparently tries to respond appropriately but response is below expected level.

11. CLIENT RELATING IRRELEVANT Talking and/or responding in a manner unrelated to changing INFORMATION AND/OR ASKING IRRELEVANT QUESTIONS speech patterns. 
APPENDIX G

CONOVER ANALYSIS SYSTEM

Category

1. AUTHORITY

2. INFORMATION

3. MODEL

4. STIMULUS

5. REWARD

6. PUNISHMENT

7. SOCIAL

8. QUESTION

9. CORRECT RESPONSE

10. INCORRECT RESPONSE

11. SOCIAL
Symbo1

Explanation

A

I

M

ST

R

P

So

Q

CR

IR

S a clicker. related to the therapy task.
Clinician exhibits behavior calculated to bring client's attention back to the task and/or inhibit client's nontherapy behavior. Ex. "Sit down" - "You're not listening."

Clinician provides background information, explanation of the therapy task to be attempted. Ex. "We are going to work on the /s/ sound." - "I want you to tell me whether I am making a $/ \theta /$ or $/ \mathrm{s} /$."

Clinician shows how to make a sound or says a sound or word to be repeated by the client.

Clinician presents a picture or an object in order to evoke a response from the client. Indirect intervention by the clinician.

Clinician gives a positvie response to a client response; i.e., intangible: "good" or tangible: chips or clink of a clicker.

Clinician gives a negative response to a client response; i.e., intangible: "no" or tangible: removal of chips or clicks of

Any response made by the clinician not

Client asks a question related to the therapy task. He may be asking for classification or reinforcement; i.e., "Should I say the whole word or just the sound?" "Was that right?"

Client gives correct response to model or stimulus presented by the clinician.

Client gives incorrect response to model or stimulus presented by the clinician.

Any response made by the client not related to the therapy task. 


\section{APPENDIX H}

\section{SAMPLE OF A FIVE-MINUTE}

THERAPY SEGMENT

\begin{tabular}{|c|c|c|}
\hline M & IR & M \\
\hline CR & M & CR \\
\hline $\mathrm{R}$ & CR & R \\
\hline ST & S & ST \\
\hline CR & CR & IR \\
\hline $\mathrm{R}$ & $\mathrm{R}$ & P \\
\hline I & so & IR \\
\hline S & ST & M \\
\hline So & I & IR \\
\hline I & CR & P \\
\hline ST & $\mathrm{R}$ & IR \\
\hline CR & CR & $\mathrm{M}$ \\
\hline $\mathrm{R}$ & $\mathbf{R}$ & IR \\
\hline CR & so & M \\
\hline CR & S & IR \\
\hline $\mathrm{R}$ & CR & M \\
\hline ST & so & IR \\
\hline CR & ST & CR \\
\hline $\mathrm{R}$ & CR & $\mathbf{R}$ \\
\hline CR & I & CR \\
\hline $\mathrm{R}$ & CR & so \\
\hline ST & $\mathrm{R}$ & IR \\
\hline CR & ST & M \\
\hline $\mathrm{R}$ & IR & IR \\
\hline ST & M & M \\
\hline M & IR & IR \\
\hline CR & $P$ & P \\
\hline CR & I & IR \\
\hline
\end{tabular}




\section{RATIO TITLE}

CORRECT RESPONSE RATIO:

INCORRECT RESPONSE RATIO:

GOOD EVALUATIVE RATIO:

BAD EVALUATIVE RATIO:

DIRECT CONTROL RATIO:

\section{DESCRIPTION}

It is the number of Correct Responses (CR) divided by the total number of Correct Responses (CR) plus the number of Incorrect Responses (IR) to determine the percentage of correct responses.

It is the number of Incorrect Responses (IR) divided by the number of Correct Responses (CR) plus the number of Incorrect Responses (IR) to determine the percentage of incorrect responses.

It is the number of Correct Responses (CR) divided by the number of Rewards (R) with the resulting number divided by the number of Correct Responses (CR) to determine the percentage of positive reinforcement.

It is the number of Incorrect Responses (IR) divided by the number of Punishments (P) with the resulting number divided by the number of Incorrect Responses (IR) to determine the percentage of punishment.

INAPPROPRIATE RESPONSE RATIO: It is the number of Social (S) responses of the client divided by the sum of Questions (Q) plus Correct Responses (CR) plus Incorrect Responses (IR) plus the number of Social (S) responses to determine the percentage of inappropriate responses.

It is the number of Social (S) responses divided by the sum of the total number of Authority (A), Instruction (I), Model (M), and Stimulus (St) responses. The resulting number is then divided by the number of Social (S) responses to determine the percentage of the clinician's control of the session. 
RATIO TITLE

SOCIALIZATION RATIO:
DESCRIPTION

It is the total of the clinician's Social (So) responses plus the total of the clients Social (S) responses divided by the total number of interactions to determine the percentage of socializing occuring during a session. 
Clinician:

Client:
Date:

Objective:

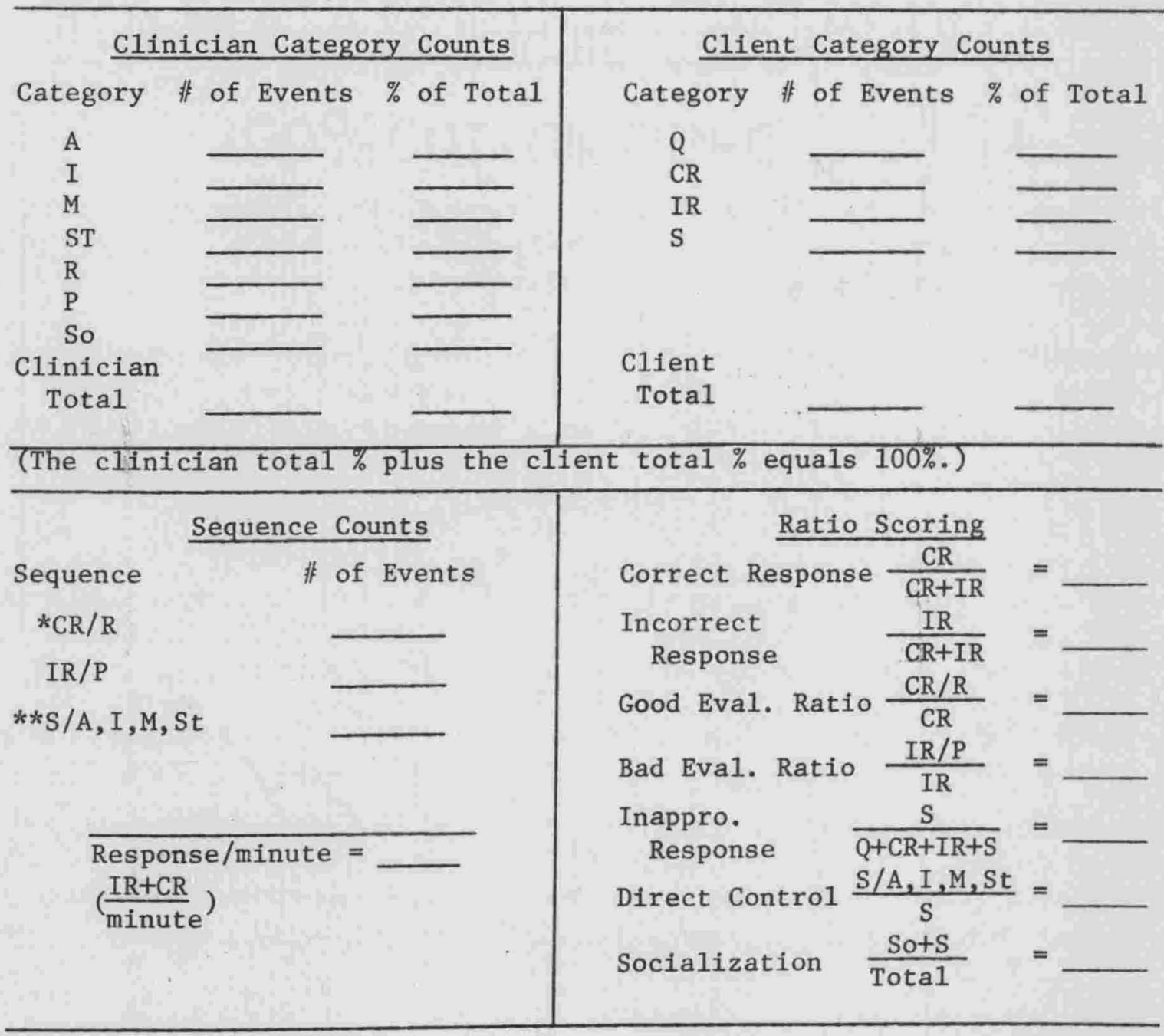

* "/" - a slash indicates the first response (CR) immediately followed by a second response (R)

** "," - a comma is substituted for "or" e.g., S/A or, I, or, M, or St. Adapted by Mary E. Gordon (1975) from the Boone-Prescott (1972) Speech and Hearing Therapy Session Scoring Form. 